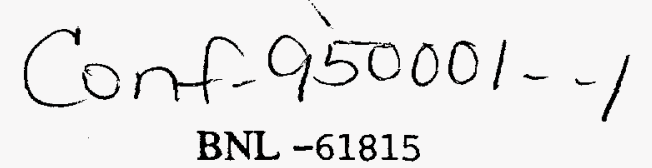

\title{
ENHANCED SHORTWAVE CLOUD RADIATIVE FORCING DUE TO ANTHROPOGENIC AEROSOLS
}

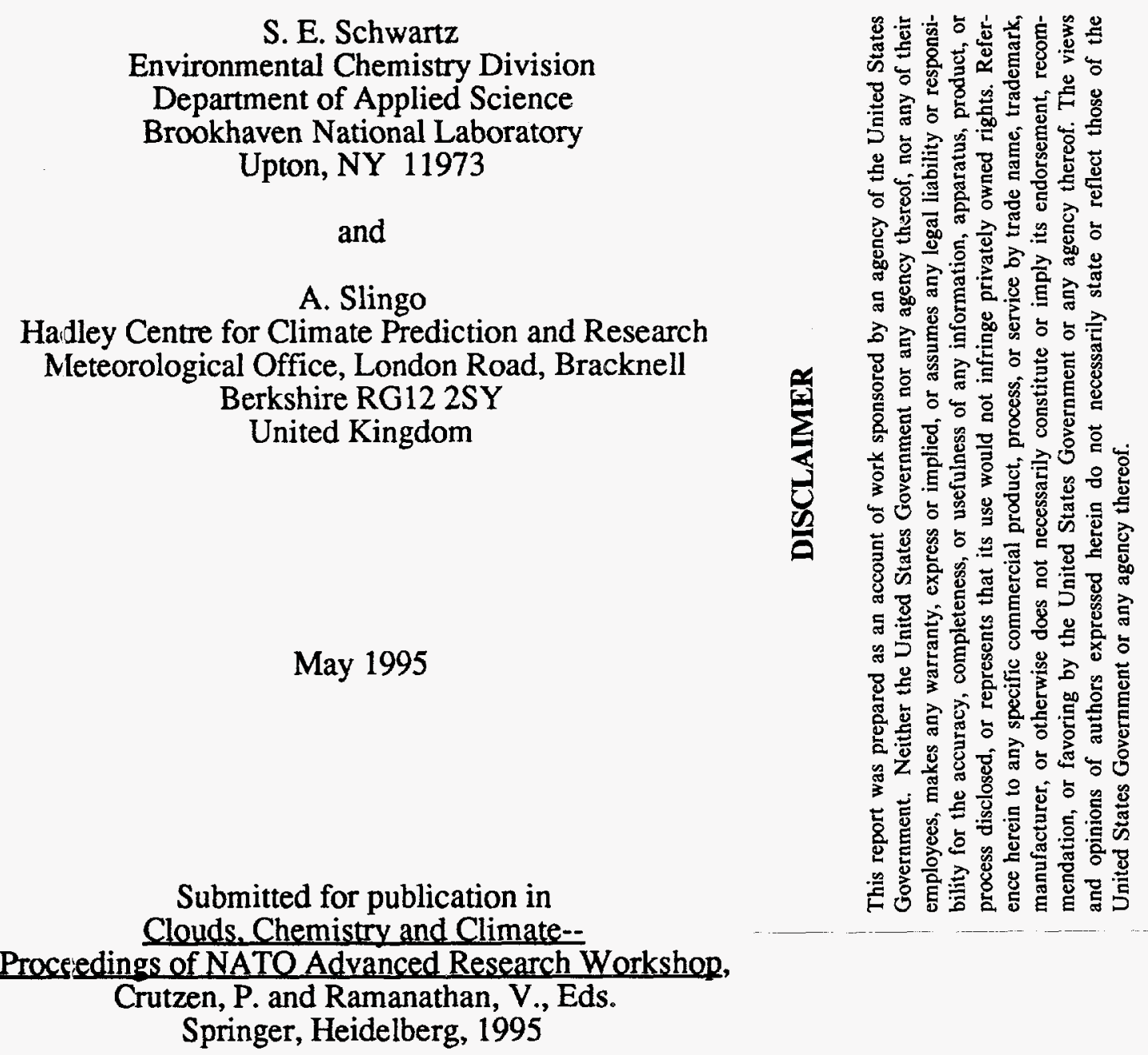

By acceptance of this article, the publisher and/or recipient acknowledges the U.S. Government's right to retain a non exclusive, royalty-free license in and to any copyright covering this paper.

This research was performed under the auspices of the U.S. Department of Energy under Contract No. DE-AC02-76CH00016. 


\section{DISCLAIMER}

Portions of this document may be illegible in electronic image products. Images are produced from the best available original document. 


\title{
ENHANCEI) SHORTWAVE CLOUD RADIATIVE FORCING \\ DUE TO ANTHROPOGENIC AEROSOLS
}

\author{
S. E. Schwartz \\ Environmental Chemistry Division \\ Brookhaven National Laboratory \\ Upton NY 11973 USA
}

and

\begin{abstract}
A. Slingo
Hadley Centre for Clinate Prediction and Research

Meteorological Office, London Road, Bracknell

Berkshire RG12 2SY LK
\end{abstract}

It has been suggested, originally by Twomey (SCEP, 1970), that anthropogenic aerosols in the troposphere can influence the microphysical properties of clouds and in turn their reflectivity (albedo), thereby exerting a radiative influence on climate. This chapter presents the theoretical basis for of this so-called indirect forcing and reviews pertinent observational evidence and climate model calculations of its magnitude and geographical distribution. We restrict consideration to liquid-water clouds, in part because these clouds are the principal clouds thought to be influenced by anthropogenic aerosols, and in part because the processes responsible for nucleation of ice clouds are not sufficiently well understood to permit much to be said about any anthropogenic influence. The argument for anthropogenic influence on cloud albedo rests on the premise that aerosol particle number concentrations are substantially increased by industrial emissions. As a consequence, the number concentration of cloud droplets $N_{\mathrm{cd}}$, which is determined by the number concentration of aerosol particles in the precloud air, is also increased. This in turn leads to an enhanced multiple scattering of light within clouds and to an increase in the optical depth and albedo of the cloud. In contrast the physical thickness, liquid water content, and liquid water path of the cloud, which are governed to close approximation by large-scale thermodynamics, are considered to be unchanged or at least not greatly influenced by the increase in cloud droplet concentration. There is evidence that this assumption may not be entirely correct. In particular there is indication that the decrease in drop size may inhibit precipitation development, increasing cloud liquid water content and cloud lifetime, both of which effects would contribute 
further to reflection of solar radiation by clouds; this phenomenon is also considered here.

The present chapter reviews the theory of the indirect forcing phenomenon and estimates of its magnitude, field measurements addressing aspects of this phenomenon, and approaches to describing this phenomenon in climate models. This review is necessarily fairly selective. For more extended accounts see Hobbs (1993), Andreae (1995), and Charlson and Heintzenberg (1995).

\section{THEORETICAL BASIS OF INDIRECT FORCING}

Aerosol influences on cloud albedo and shortwave forcing. The theoretical basis for a dependence of cloud albedo on cloud droplet number density, and in turn on the number density of the aerosol particles on which cloud droplets form, is outlined by Twomey $(1974,1977 \mathrm{a}, \mathrm{b})$. To relate cloud albedo to optical depth and thus to microphysical properties we employ an analytical expression obtained from the two-stream approximation for the reflectance (albedo) $R_{\mathrm{CT}}$ of a nonabsorbing, horizontally homogeneous cloud (e.g., Bohren, 1987):

$$
R_{\mathrm{CT}}=\frac{\delta_{\mathrm{C}}(1-g)}{2+\delta_{\mathrm{C}}(1-g)} \text {. }
$$

Here $g$ is the asymmetry parameter for single scattering (mean cosine of the scattering angle), approximately 0.85 for cloud droplets of radius much greater than the wavelength of visible light, and $\delta_{\mathrm{C}}$ is the optical depth of the cloud,

$$
\delta_{\mathrm{C}}=\int d z \int \pi Q_{\mathrm{ext}}(r) r^{2} N(r) d r .
$$

Here $Q_{\text {ext }}(r)$ is the extinction efficiency for a cloud droplet of radius $r$, and $N(r)$ is the size distribution of the cloud drops; the integrals are taken over drop radius and the physical depth of the cloud. For cloud droplets of radius much greater than the wavelength of visible light $Q_{\text {ext }}(r)$ may be approximated as a constant, $Q_{\text {ext }} \approx 2$ (twice the geometric cross section; Twomey, 1977a). Hence for a uniform cloud

$$
\delta_{\mathrm{C}} \approx 2 \pi \overline{r^{2}} N_{\mathrm{cd}} z_{\mathrm{C}},
$$

where $z_{\mathrm{C}}$ is the physical thickness of the cloud layer, $N_{\mathrm{cd}}$ is the cloud droplet number concentration, and $\overline{r^{2}}$ is the mean square drop radius given by

$$
\overline{r^{2}}=\frac{1}{N_{\mathrm{cd}}} \int r^{2} N(r) d r .
$$




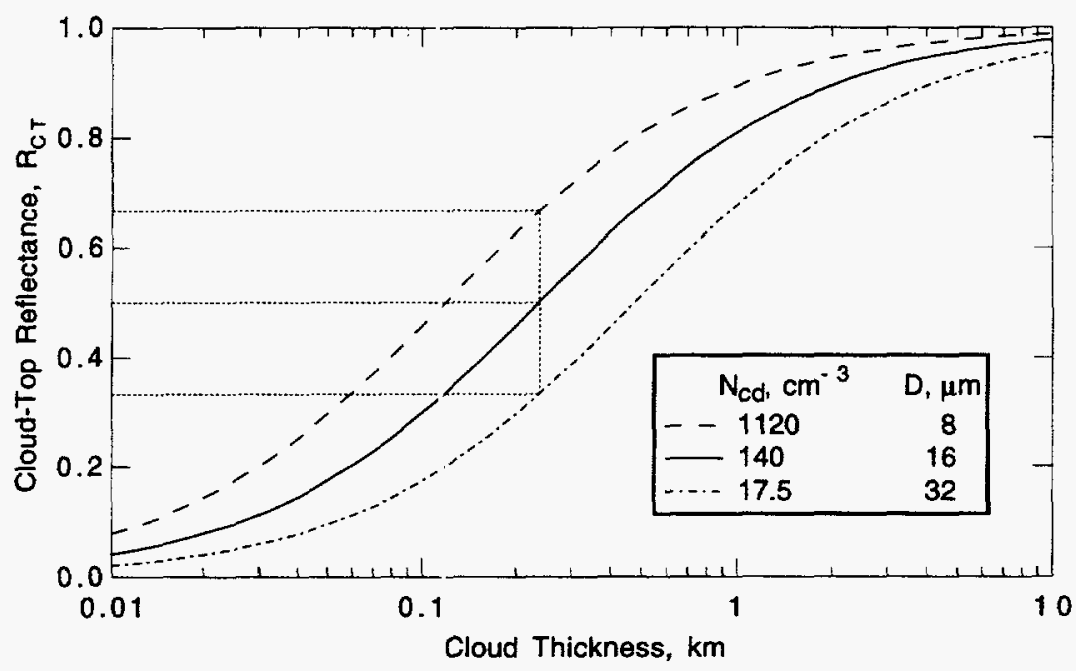

Figure 1. Dependence of cloud-top albedo on cloud thickness for liquid water volume fraction $L=0.3 \mathrm{~cm}^{3}$ $\mathrm{m}^{-3}$ and indicated values of cloud droplet number concentration $N_{\mathrm{cd}}$. Note that the sensitivity to an eightfold increase/decrease in $N_{\text {cd }}$ (halving/doubling, respectively, of drop diameter) is greatest for clouds of intermediate reflectance $R_{\mathrm{CT}}=0.5$ and falls off for both greater and lesser values of $R_{\mathrm{CT}}$. Modified from Twomey (1977a).

To examine the depenclence of $R_{\mathrm{CT}}$ on $N_{\mathrm{cd}}$ we note that for a cloud of fixed liquid water volume fraction $L$, the drop radius and number concentration are not independent, but are related by $L=(4 \pi / 3) \overline{r^{3}} N_{\mathrm{cd}}$, where $\overline{r^{3}}$ is the mean cube drop radius. Thus, within the approximation $\overline{r^{3}}=\overline{r^{2}} 3 / 2$,

$$
\delta_{\mathrm{C}} \approx 2 \pi z_{\mathrm{C}}\left(\frac{3 L}{4 \pi}\right)^{2 / 3} N_{\mathrm{cd}}^{1 / 3}
$$

More accurately

$$
\delta_{\mathrm{C}}=2 \pi z_{\mathrm{C}}\left(\frac{3 L}{4 \pi}\right)^{2 / 3} \kappa^{1 / 3} N_{\mathrm{cd}}^{1 / 3},
$$

where $\mathrm{\kappa}$ is a dimensionless measure of the dispersion of the drop size distribution

$$
\mathrm{K} \equiv{\overline{r^{2}}}^{3} /{\overline{r^{3}}}^{2} \text {. }
$$

For any given shape of the drop size distribution, $\kappa$ is a constant of value near unity; the value of $\kappa$ varies slightly for distributions of different shapes.

Equations (1) and (3a) can be used to evaluate the cloud-top albedo as a function of physical thickness of cloud, for specified values of $L$ and $N_{\mathrm{cd}}$, Figure 1, or as a function of $N_{\mathrm{cd}}$ for specified values of $L$ and $z_{\mathrm{C}}$, Figure 2 .

Equations (1) and (3a), being analytical, allow an expression to be derived for the sensitivity of cloud-top albedo to a change in $N_{\mathrm{cd}}$, for fixed liquid water content and physical thickness of cloud: 


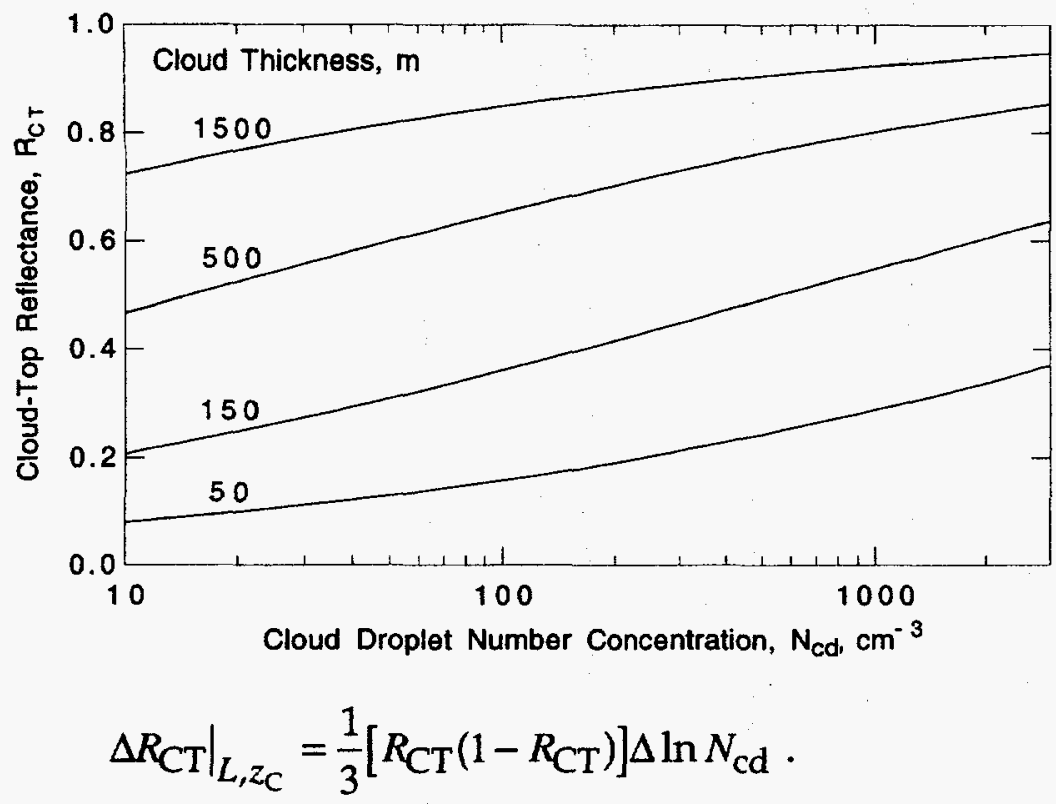

Figure 2. Dependence of cloud-top albedo on cloud droplet number concentration $N_{\text {cd }}$ for liquid water volume fraction $L=0.3 \mathrm{~cm}^{3} \mathrm{~m}^{-3}$ and indicated values of cloud thickness.

The quantity $R_{\mathrm{CT}}\left(1-R_{\mathrm{CT}}\right)$ exhibits maximum value of $1 / 4$ when cloud-top albedo $R_{\mathrm{CT}}=1 / 2$, for which $\Delta R_{\mathrm{CT}}$ assumes a maximum value $\Delta R_{\mathrm{CT}}^{\max }=1 / 12 \Delta \ln N_{\mathrm{cd}}$. As seen in Figure 3, the sensitivity of cloud-top albedo to change in cloud droplet concentration varies only slowly with $R_{\mathrm{CT}}$ for intermediate values of $R_{\mathrm{CT}}$. The approximation

$$
\left.\Delta R_{\mathrm{CT}}\right|_{L, z_{\mathrm{C}}} \approx 0.075 \Delta \ln N_{\mathrm{cd}}
$$

is accurate within $10 \%$ for the range of cloud-top albedo $0.28 \leqslant R_{\mathrm{CT}} \leqslant 0.72$. This range of albedo is characteristic of the prevalent and climatically important marine stratus clouds.

It should be noted that the above calculations are referred to a fractional change in $N_{\mathrm{cd}}, \Delta \ln N_{\mathrm{cd}}=\Delta N_{\mathrm{cd}} / N_{\mathrm{cd}}$. Twomey (1991) introduces what he refers to as an absolute cloud susceptibility,

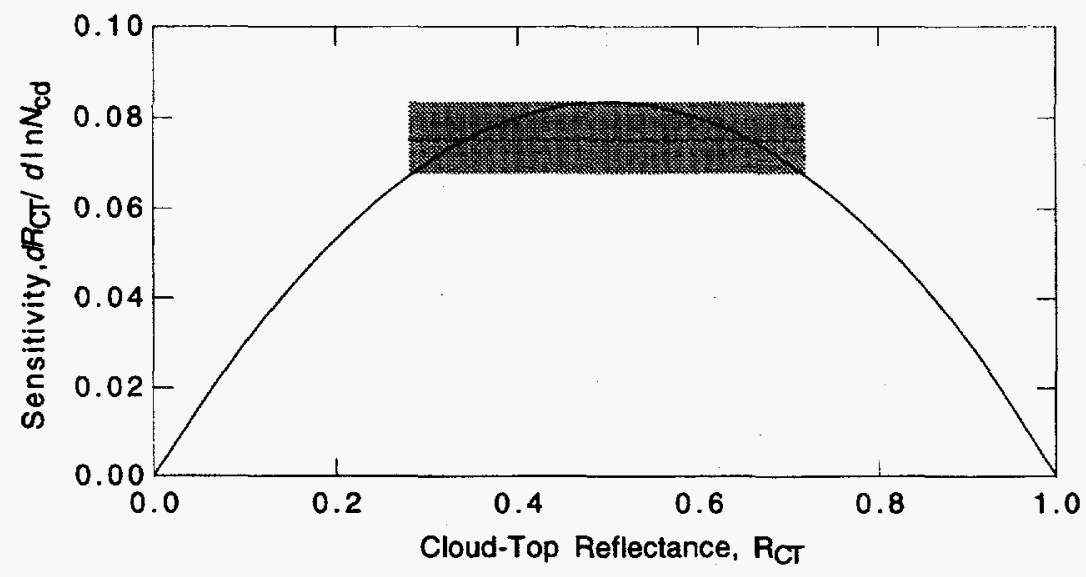

Figure 3. Dependence of sensitivity of cloud-top albedo $R_{\mathrm{CT}}$ to a logarithmic change in concentration of cloud droplet number concentration $N_{\mathrm{cd}}$, as a function of $R_{\mathrm{CT}}$. The shaded band indicates the region, $0.28 \lesssim R_{\mathrm{CT}} \lesssim 0.72$, for which the approximation $d R_{\mathrm{CT}} / d \ln N_{\mathrm{cd}} \approx 0.075$ h o $1 \mathrm{~d} \mathrm{~s}$ within $10 \%$. Modified from Charlson et al. (1992). 


$$
\frac{d R_{\mathrm{CT}}}{d N_{\mathrm{cd}}}=\frac{1}{3 N_{\mathrm{cd}}}\left[R_{\mathrm{CT}}\left(1-R_{\mathrm{CT}}\right)\right]
$$

and points out that this quantity is greatest in regions where values of $N_{\mathrm{cd}}$ are low, such as remote rnaritime locations. Platnick and Twomey (1994) and Taylor and McHaffie (1994) have evaluated cloud susceptibilities according to this definition, finding not surprisingly, that the susceptibility decreases strongly as the total cloud droplet: concentration increases.

Twomey (1977b) carried out numerical calculations to examine the influence that absorbing material in aerosol particles would exert on the albedo enhancement due to increasing droplet concentrations. He found that except for clouds having very high albedo $\left(R_{\mathrm{CT}} \lesssim 0.8\right)$, the albedo enhancement dominated over the albedo decrease due to absorbing material for reasonable assumptions of the magnitude of the absorption.

To gain a sense of the magnitude of albedo change and forcing that would be associated with a possible anthropogenic perturbation in $N_{\mathrm{cd}}$, we note that a $10 \%$ relative increase in $N_{\mathrm{cd}}\left(\Delta \ln N_{\mathrm{cd}} \approx 0.1\right)$ corresponds to an increase in absolute cloud-top albedo by nearly $1 \%(0.75 \%)$. This high sensitivity to $N_{\mathrm{cd}}$, together with the large amount of shortwave power reflected by clouds, is the basis of the sensitivity of the so-called indirect aerosol forcing effect and may be used to make a initial estimate of the magnitude of global mean radiative forcing that might be attributable to anthropogenic aerosols. Data from the Earth Radiation Budget Experiment (ERBE; Hartmann, 1993) show that the high albedo of clouds, relative to that of the cloud-free surface, increases the global-average reflection of shortwave radiation by about $50 \mathrm{~W} \mathrm{~m}^{-2}$. If anthropogenic aerosols increase Northern Hemisphere-average cloud droplet number concentrations by $30 \%$, as estimated (Schwartz, 1988) on the basis of comparisons of non-seasalt sulfate concentrations in remote Northern Hemisphere and Southern Hemisphere marine locations, then the resultant cloud brightening due to these aerosols would result in a hemispheric-mean forcing of $-1.1 \mathrm{~W} \mathrm{~m}^{-2}$, although, to be sure, not all such clouds are low-level clouds susceptible to anthropogenic aerosol influence. To place this forcing in the context of greenhouse gas forcing, we note that the longwave radiative forcing by increases in $\mathrm{CO}_{2}$ over the industrial period is about $1.5 \mathrm{~W} \mathrm{~m}^{-2}$, and the total for all greenhouse gases over this period is about $2.5 \mathrm{~W} \mathrm{~m}^{-2}$ (Shine et al., 1990). This forcing is also comparable to recent estimates of the direct shortwave forcing due to light scattering by anthropogenic aerosols 
in cloud-free conditions (Charlson et al., 1991, 1992; Kiehl and Briegleb, 1993; Taylor and Penner, 1994). Thus the indirect forcing by anthropogenic aerosols, as well as the direct forcing, needs to be taken into account in the context of anthropogenic influences on climate (Wigley, 1994; IPCC, 1995).

A somewhat different approach to estimating the global mean forcing due to anthropogenic aerosols was taken by Charlson et al. (1992; cf. also Kaufman et al., 1991), who attempted to assess the global-mean forcing based on the fractional coverage of marine stratus clouds. For a given cloud-top albedo perturbation the corresponding perturbation in top-of-atmosphere (TOA) albedo is

$$
\Delta R_{\mathrm{TOA}}=T^{2} \Delta R_{\mathrm{CT}}
$$

where $T$ is the fraction of incident shortwave radiation transmitted by the atmosphere above the cloud layer. To obtain the change in global- or hemispheric-mean albedo due only to the change in albedo of marine stratus clouds $\Delta R_{\mathrm{TOA}}^{\mathrm{mst}}$, the albedo change given by (7) must be decreased further by the fractional coverage by marine stratus clouds, $A_{\text {mst }}$ yielding

$$
\overline{\Delta R_{\mathrm{TOA}}}=A_{\mathrm{mst}} \Delta R_{\mathrm{TOA}}^{\mathrm{mst}} \text {. }
$$

The corresponding perturbation in global- or hemispheric-mean shortwave forcing was estimated as

$$
\overline{\Delta F_{\mathrm{C}}}=-\bar{F} \overline{\Delta R_{\mathrm{TOA}}}=-\left(F_{\mathrm{T}} / 4\right) \overline{\Delta R_{\mathrm{TOA}}},
$$

where $\bar{F}$ is the global- or hemispheric-mean top-of-atmosphere shortwave radiation evaluated as $\bar{F}=F_{\mathrm{T}} / 4$, where $F_{\mathrm{T}}$ is the solar constant. The negative sign denotes a cooling tendency. The forcing depends linearly on the perturbation in cloud-top albedo and thus exhibits a logarithmic dependence on $N_{\text {cd }}$ given by (5).

$$
\overline{\Delta F_{\mathrm{C}}} \approx-0.075\left(F_{\mathrm{T}} / 4\right) A_{\mathrm{mst}} T^{2} \Delta \ln N .
$$

Figure 4 shows the dependence of global- or hemispheric-mean radiative forcing on a change in $N_{\mathrm{cd}}$ and indicates a sensitivity comparable to that estimated above. For an assumed $30 \%$ increase in hemispheric-mean $N_{\mathrm{cd}}$, the hemispheric-mean forcing evaluated by this approach is $-1.1 \mathrm{~W} \mathrm{~m}^{-2}$, identical to that obtained using the cloud radiative forcing determined from the ERBE data.

As discussed below, more detailed model calculations lead to estimates of similar magnitude, although it must be emphasized that the premise of the estimate 


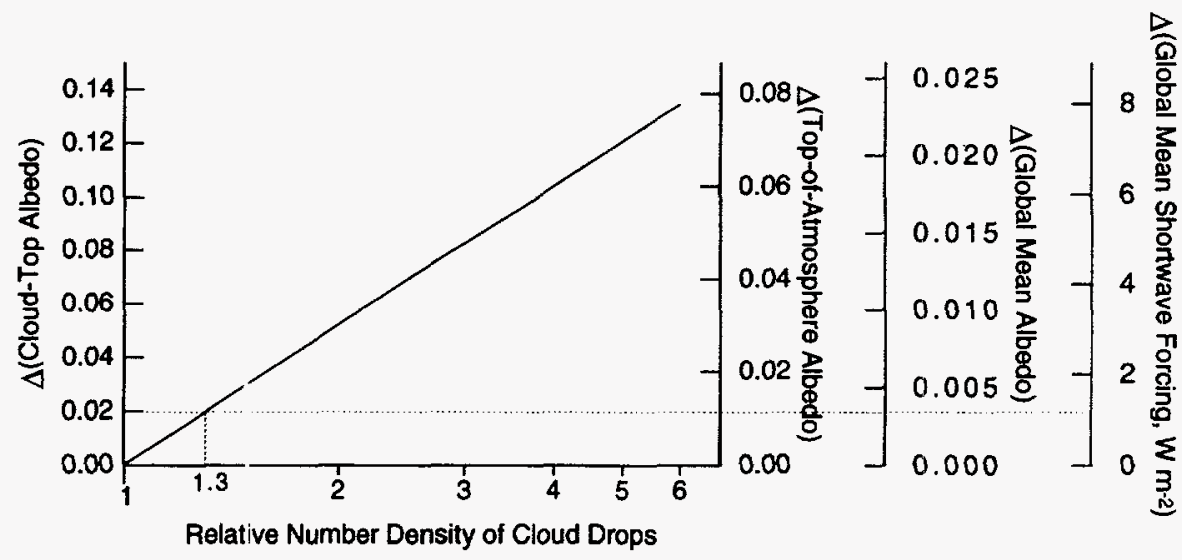

Figure 4. Calculated perturbation in cloud-top albedo (left ordinate), top-of-atmosphere albedo above marine stratus, global-mean albedo, and global-mean cloud radiative forcing (right ordinates) resulting from a uniform increase in cloud droplet number concentration $N_{\mathrm{cd}}$ by the factor indicated in the abscissa. The global-mean calculations were made with the assumption (Charlson et al., 1987) that the perturbation affects only non-overlapped marine stratus and stratocumulus clouds having a fractional area of $30 \%$; the fractional atmospheric transmittance of shortwave radiation above the cloud layer was taken as $76 \%$. The dotted line indicates the perturbations resulting from a $30 \%$ increase in $N_{\mathrm{cd}}$. Modified from Charlson et al. (1992).

( $30 \%$ hemispheric erhancement in cloud droplet number concentrations) remains little more than an educated guess at present. Much work needs to be done before the uncertainty associated with the indirect forcing by anthropogenic aerosols, as well as that associated with the direct forcing, can be reduced to a value comparable with that associated with anthropogenic greenhouse gases (Penner et al., 1994).

Theoretical basis for anthropogenic influence on cloud droplet concentrations. Having set forth the basis for the dependence of $R_{\mathrm{CT}}$ on $N_{\mathrm{Cd}}$, we turn to examination of the influence of anthropogenic aerosols on cloud droplet concentrations $N_{\mathrm{cd}}$. In this examination we rely mainly on observations, but with guidance from theory (e.g., Pruppacher and Klett, 1980; Hänel, 1987; Hobbs, 1993) and model studies (Jensen and Charlson, 1984; Flossmann et al., 1985; Ahr et al., 1989).

First we give a quick overview of the basis for this influence. Briefly clouds form when an air parcel, which inevitably contains aerosol particles as well as water vapor, is cooled to a temperature below its dew point and water vapor condenses on existing aerosol particles to form cloud droplets. As the temperature decreases to and below the dew point, the ambient water vapor pressure exceeds the equilibrium water vapor pressure characterizing the aqueous (hygroscopic or deliquescent) aerosol particles present in the air. This departure from 
equilibrium leads to net condensation of water on the particles. The condensation on any given particle tends to be resisted by the energy required to create the additional surface area of the growing droplet and favored by the vapor pressure reduction resulting from the presence of soluble material in the particles. The combined influence of these competing effects results in a freeenergy barrier that is characterized by a critical drop radius and vapor pressure whose values depend on the solute mass and composition. The value of the critical vapor pressure decreases with increasing solute mass because of surfaceto-volume considerations.

During the initial stage of droplet growth the surface free-energy term is dominant, and the accretion of additional water by a droplet increases its equilibrium water vapor pressure, tending to inhibit further growth. However, if the ambient vapor pressure of water exceeds the critical vapor pressure of a given particle for sufficiently long that the radius of the nascent cloud drop grows beyond its critical value, then further droplet growth decreases its equilibrium water vapor pressure, and consequently the droplet will continue to grow even as the ambient vapor pressure subsequently decreases. This process is referred to as cloud droplet "activation." After the initial peak in supersaturation in the early stage of cloud formation, the surface area of the growing drops provides an increasing sink for water vapor and the ambient supersaturation decreases. Larger particles, which have been activated, continue to grow; smaller particles, which were not activated, shrink and remain as "interstitial" aerosol particles.

The number of aerosol particles activated during cloud formation depends on the number of aerosol particles present in the pre-cloud air that were sufficiently large, and containing a sufficient amount of hygroscopic material, to have become activated given the time history of supersaturation at the early stage in the cloud cycle. This supersaturation time profile depends in the first instance on the time profile of the thermodynamic driving force--the updraft velocity and the resultant rate of generation of supersaturation, or, more precisely, the rate of decrease of the saturation vapor pressure of water. Thus the number concentration of cloud droplets might be expected to increase with the number concentration of aerosol particles of a size range suitable to become activated for a given maximum supersaturation. However this dependence is not a simple oneto-one relation because the supersaturation time profile itself depends on the aerosol loading, since a greater concentration of particles and the associated surface area available for water condensation will lead to a reduced ambient 
supersaturation for a given thermodynamic generation rate. One will thus expect a decrease from a one-to-one relation as aerosol particle concentrations become sufficiently great. Horvever the onset of the fall off may be expected to depend on updraft velocity, insofar as this variable controls the generation rate of supersaturation. It is in the context of this picture that we examine the influence of perturbations on cloud droplet concentrations due to anthropogenic aerosols.

In consideration of anthropogenic influences on $\mathrm{CCN}$ and cloud droplets much attention has been focused on sulfur compounds, since sulfate comprises a major fraction of accumulation-mode (radius $\sim 0.1$ to $1 \mu \mathrm{m}$ ) aerosol particles and since sulfuric acid and its neutralization products (collectively, sulfate) are highly water-soluble and therefore effective atmospheric aerosols. The mechanism by which $\mathrm{SO}_{2}$, the major emitted species, is oxidized to form sulfate and by which the aerosol forms and grows to a size that is effective as $\mathrm{CCN}$ at modest supersaturations is not fully established. $\mathrm{SO}_{2}$ is oxidized in the gas phase and hydrated to form sulfuric acid monomer, which, because of its low vapor pressure, adds to existing particles or forms new particles depending on the formation rate and the available surface area. However concerns have been raised that the aerosol growth process is too slow to account for particles that serve as $\mathrm{CCN}$ at low updraft velocities characteristic of marine stratus clouds. $\mathrm{SO}_{2}$ is oxidized also in aqueous solution, in clear-air particles and in cloud droplets. It is of course tautologicil that concentrations of aerosol particles can increase only by mechanisms involving new particle formation. Nonetheless aqueous-phase oxidation may contribute substantially to the process by which particles grow to a size sufficiently great to serve as CCN in marine stratus (Fitzgerald, 1991; Hegg, 1990; Lin et al., 1992; Lelieveld and Heintzenberg, 1992; Kaufman and Tanré, 1994). Other anthropogenic materials that are thought to contribute substantially to CCN are nitrates, i.e.., nitric acid and its salts, (Kulmala et al., 1993; Wurzler et al., 1995) and organics, including those from biomass combustion (Warner and Twomey, 1967; Novakov and Penner, 1993; Andreae, 1995). On the other hand, there is a growing body of evidence that, depending on composition, not all particles of a given size serve equally well as $\mathrm{CCN}$, and that even in a given cloud the fraction of insoluble material present on particles that are activated to form cloud drops increases with increasing particle size (Hansson and Svenningsson, 1994; Hallberg et al., 1994).

Influence of cloud droplet concentrations on cloud lifetime. An additional influence of anthropogenic $\mathrm{CCN}$ on shortwave cloud radiative forcing may come 
from an increase in cloud lifetime. The formation of precipitation within clouds is strongly dependent on the size distribution of cloud droplets; warm precipitation develops much more efficiently for a given liquid water content in clouds with fewer, larger drops than in clouds with more, smaller drops. Albrecht (1989) described potential increases in cloud lifetime if precipitation rates were reduced by a decrease in cloud droplet size due to anthropogenic CCNs and called attention to the climatic implications of this effect. Ackerman et al. (1993) presented model results describing the collapse of stratus cloud formation processes from a deficit of $\mathrm{CCN}$, providing further indication that additional $\mathrm{CCN}$ could stabilize a cloud against dissipation by drizzle. This phenomenon gains support by the occurrence of ship tracks in cloud free regions.

In addition to the shortwave radiative influence, enhanced persistence of clouds due to anthropogenic aerosols can also exert a longwave influence, since a more persistent cloud will absorb and radiate in the thermal infrared as well as reflect shortwave radiation. Further, to the extent that water that would otherwise be precipitated remains in the atmosphere as vapor, that water vapor will exert an additional greenhouse influence. It thus appears that representation of these effects in climate models will require a considerable extension of the treatment of cloud processes beyond that in which cloud processes are governed by large scale thermodynamics alone.

\section{OBSERVATIONAL STUDIES}

We review here observations relating mass concentrations of aerosol constituents and number concentrations of aerosol particles, cloud condensation nuclei, and cloud droplets. Unfortunately there are few studies relating all of these variables; typically only two quantities are measured at a time, and thus it is not possible to characterize the linkage among all these quantities even in a single study, and all the more in any climatologically meaningful way. On the other hand there are a large number of studies looking at pieces of the picture; the studies described here should be considered as representative of that larger set.

Anthropogenic influences on $\mathrm{CCN}$ concentrations. A key determinant of aerosol influences on cloud droplet concentrations is the number concentration of cloud condensation nuclei, $\mathrm{CCN}$, particles which will activate to form cloud droplets at a given supersaturation, maintained indefinitely. $\mathrm{CCN}$ concentrations are thus not equal to cloud droplet number concentrations, but are a convenient means of characterizing the cloud nucleating ability of a given air sample. CCN 
concentrations may be determined experimentally by exposing an ambient air sample to a known supersaturation (typically $0.3 \%$ to $1.5 \%$ ) for sufficiently long to activate all particles whose critical supersaturation is less than or equal to the imposed supersaturation and counting the resultant droplet concentration, which is manifest by the enhanced light scattering. (Twomey, 1977a; Twomey et al., 1978). In a given air sample the CCN number concentration increases with increasing supersaturation, consistent with the depiction of the activation process given above. Because of this dependence it is necessary to specify the supersaturation characterizing a given $\mathrm{CCN}$ concentration measurement and to compare measurements only at a specified supersaturation.

It has been known for some time that $\mathrm{CCN}$ concentrations are greater in continental air masses than in marine air masses--by a factor of perhaps three or more. Summarizing numerous studies, Pruppacher and Klett (1980) conclude that $\mathrm{CCN}$ concentrations in maritime air uninfluenced by anthropogenic emissions rarely exceed $100 \mathrm{~cm}^{-3}$, whereas in air that has been over land for several days concentrations in excess of $1000 \mathrm{~cm}^{-3}$ are frequent. As discussed below, however, it is slear that much of the so-called continental enhancement must be attributable to anthropogenic influences. With respect to natural $\mathrm{CCN}$, Twomey (1977a) reports observations of vertical profiles of CCN concentrations over Colorado (surface concentration $230 \mathrm{~cm}^{-3}$ at $0.35 \%$ supersaturation) and the Caribbean $\left(80 \mathrm{~cm}^{-3}\right)$. At both locations $\mathrm{CCN}$ concentrations decrease with increasing altitude, indicative of a surface source. On the basis of such observations and the lack of any indication of direct emission of $\mathrm{CCN}$ from surfaces, Twomey suggests that the principal natural source of $\mathrm{CCN}$ is particle formation in the atmosphere from gases emitted at the surface and that these emissions are greater over vegetated land surfaces than over oceans. Mészáros (1992), likewise, consiclers the surface to be the principal source of $\mathrm{CCN}$, but hypothesizes that in the absence of anthropogenic sources, continental CCN concentrations may be substantially less than marine. For another view, however, see Slinn (1992) and Raes (1995), who argue on behalf of the contribution of natural $\mathrm{CCN}$ formed in the free troposphere from gas to particle conversion and subsequent particle growth. Ayers and Gras (1991) present data obtained in air minimally influenced by anthropogenic emissions at Cape Grim, Tasmania, indicative of a dependence of CCN concentrations (50 to $150 \mathrm{~cm}^{-3}$ at $0.2 \%$ supersaturation) on the concentration of methanesulfonic acid, an oxidation product of marine dimethylsulfide (DMS). 
Table 1. Summary of CCN concentration data upwind and downwind of St. Louis (Braham, 1974)

\begin{tabular}{|c|c|c|c|c|c|c|c|}
\hline \multirow[t]{2}{*}{ Dates } & \multirow[t]{2}{*}{$\begin{array}{l}\text { Sampling } \\
\text { level } \\
\text { (m, msl) }\end{array}$} & \multirow{2}{*}{$\begin{array}{l}\text { Number of } \\
\text { upwind- } \\
\text { downwind } \\
\text { comparisons }\end{array}$} & \multirow{2}{*}{$\begin{array}{l}\text { Number of } \\
\text { days } \\
\text { downwind } \\
\text { CCN }(0.5 \%) \\
>\text { upwind }\end{array}$} & & \multicolumn{3}{|c|}{$\begin{array}{c}\mathrm{CCN} \text { concentrations at various } \\
\text { supersaturations }\end{array}$} \\
\hline & & & & & $0.35 \%$ & $0.5 \%$ & $1.0 \%$ \\
\hline \multirow{3}{*}{$\begin{array}{l}\text { Jul-Aug, } \\
1971\end{array}$} & \multirow[t]{3}{*}{610} & \multirow[t]{3}{*}{19} & \multirow[t]{3}{*}{19} & $N(u)$ & 1071 & 1370 & 2210 \\
\hline & & & & $N(d)$ & 1770 & 2313 & 3890 \\
\hline & & & & $N(d) / N(u)$ & 1.65 & 1.69 & 1.76 \\
\hline \multirow{3}{*}{$\begin{array}{l}\text { Jan-Mar, } \\
1972\end{array}$} & \multirow[t]{3}{*}{460} & \multirow[t]{3}{*}{13} & \multirow[t]{3}{*}{12} & $N(u)$ & 355 & 477 & 848 \\
\hline & & & & $N(d)$ & 606 & 857 & 1678 \\
\hline & & & & $N(d) / N(u)$ & 1.71 & 1.80 & 1.98 \\
\hline \multirow{3}{*}{$\begin{array}{l}\text { Jul-Aug, } \\
1972\end{array}$} & \multirow{3}{*}{$\begin{array}{l}\text { top of } \\
\text { mixed layer } \\
\text { to } 460\end{array}$} & \multirow[t]{3}{*}{25} & \multirow[t]{3}{*}{23} & $N(u)$ & 602 & 753 & 1166 \\
\hline & & & & $N(d)$ & 821 & 1036 & 1625 \\
\hline & & & & $N(d) / N(u)$ & 1.36 & 1.38 & 1.40 \\
\hline \multirow{3}{*}{$\begin{array}{l}\text { Mar-Apr, } \\
1973\end{array}$} & \multirow[t]{3}{*}{460} & \multirow[t]{3}{*}{10} & \multirow[t]{3}{*}{9} & $N(u)$ & 357 & 502 & 977 \\
\hline & & & & $N(d)$ & 467 & 686 & 1451 \\
\hline & & & & $N(d) / N(u)$ & 1.31 & 1.37 & 1.49 \\
\hline
\end{tabular}

In any event, in addition to natural $\mathrm{CCN}$ it is well established that $\mathrm{CCN}$ concentrations are greatly enhanced in the vicinity of industrial activities, especially combustion, that can release massive amounts of aerosol particles and/or gaseous precursors into the atmosphere. For example Twomey (1974; see also Twomey et al., 1978) reported measurements of $\mathrm{CCN}$ concentrations at a site in southeastern Australia. Under conditions of air flow from "relatively clean" land CCN concentrations (supersaturation $0.75 \%$ ) were as low as $50 \mathrm{~cm}^{-3}$, but when the air had passed over an industrial area the concentration increased to $4500 \mathrm{~cm}^{-3}$. In a study of the influence of urban emissions on CCN concentrations Braham (1974) found substantial enhancement of CCN concentrations in comparisons of concentrations upwind and downwind of St. Louis, Missouri, as summarized in Table 1 . CCN concentrations were substantially enhanced downwind of the city on almost all days studied, with the average enhancement factor ranging from 1.31 to 1.98 . Figure 5 shows a comparison of supersaturation spectra (concentration of $\mathrm{CCN}$ versus percent supersaturation) obtained upwind and downwind of the city; at any given supersaturation the average enhancement in concentration was about a factor of 2 .

In aircraft measurements off the eastern seaboard of the United States, Radke and Hobbs (1976) reported CCN concentrations (at $0.2 \%$ supersaturation) of 1000 to $3500 \mathrm{~cm}^{-3}$ under conditions of northwesterly flow such that the air mass sampled was representative of air blowing off the continent. They compared these 


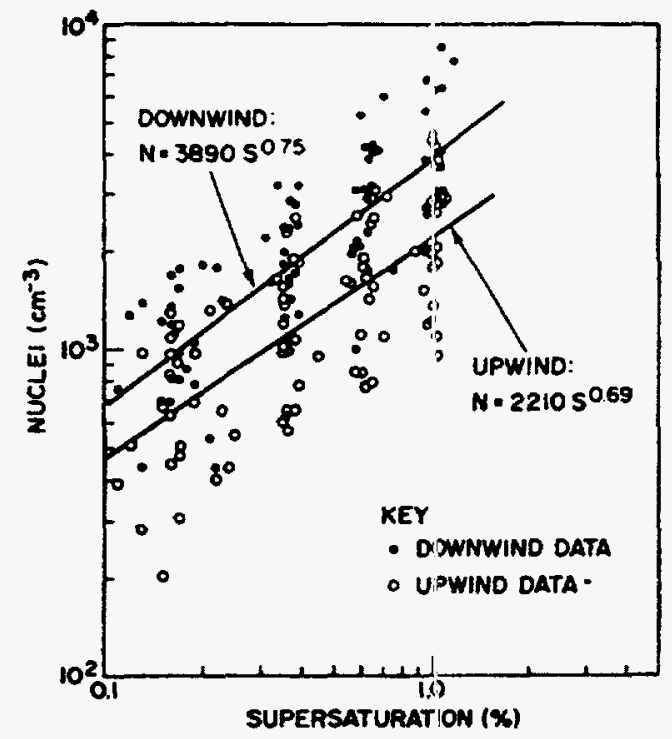

Figure 5. Dependence of CCN concentration on supersaturation measured in 19 upwind-downwind pairs of air samples collected on aircraft flights the vicinity of St. Louis, Missouri during July and August, 1971. The straight lines are log-linear regression fits to the data. (Fitzgerald and Spyers-Duran, 1973).

concentrations to those in clean maritime air masses on the Pacific Coast of Washington state (typically less than $100 \mathrm{~cm}^{-3}$ ) or over the high plains of the United States (about $300 \mathrm{~cm}^{-3}$ ). These results were interpreted as indicative of the dominance of anthropogenic $\mathrm{CCN}$ in industrial or heavily populated areas, although the investigators explicitly refrained from implying that regions far from large anthropogenic sources of $\mathrm{CCN}$ are appreciably affected by $\mathrm{CCN}$ from anthropogenic sources, in view of the short (several-day) average residence time of CCN in the atmosphere. More recently Hudson (1991) has reported measurements along the coast of California indicating a background marine concentration ( $0.7 \%$ supersaturation) of 20 to $40 \mathrm{~cm}^{-3}$, compared to "non-urban" concentrations $100 \mathrm{~km}$ inland, in Oregon, of 100 to $200 \mathrm{~cm}^{-3}$ and to "urban" concentrations in the vicinity of Santa Cruz, California of 3000 to $5000 \mathrm{~cm}^{-3}$. Frisbie and Hudson (1.993) report CCN concentrations (0.9\% supersaturation) at $800 \mathrm{hPa}$, upwind and downwind of Denver, Colorado of 500 and $5000 \mathrm{~cm}^{-3}$, respectively. These and other measurements give ample evidence of the substantial anthropogenic enhancement of $\mathrm{CCN}$ concentrations. It is clear, with reference to equation (10) or Figure 4, that if cloud droplet concentrations were to exhibit anthropogenic enhancement by factors such as those reported in these measurements of $\mathrm{CCN}$ concentrations, the perturbation on cloud albedo and the resultant radiative forcing would be enormous.

The high sensitivity of cloud albedo and radiative forcing to cloud droplet concentration thus points to a key issue, namely, the extent to which $\mathrm{CCN}$ and cloud droplet concentrations are enhanced by anthropogenic aerosols over broad regions of the marine atmosphere. This issue remains quite unresolved. 
Schwartz (1988) proposed on the basis of measurements in the North Atlantic and rather limited measurements in the North Pacific that concentrations of non-seasalt sulfate were $30 \%$ greater in the Northern Hemisphere (NH) marine environment than in the Southern Hemisphere $(\mathrm{SH})$, and by inference that the same held for CCN. This argument was challenged by Charlson et al. (1989) with respect to both the measurement database and the assumption of a linear relation between sulfate loadings and CCN concentrations. However based on long-term measurements of sulfate and methanesulfonate at a network of Pacific islands, Savoie and Prospero (1989) suggested an annual average anthropogenic enhancement of sulfate in the mid North Pacific of about $20 \%$. On the other hand, in a review of aerosol properties in the marine environment, Fitzgerald (1991) presented evidence of a rapid shift from continental to marine aerosols with increasing distance from continents. In any event it is clear that the high sensitivity of radiative forcing to increased cloud droplet concentrations (equation 10; Figure 4) not only makes it crucial that the magnitude of the anthropogenic perturbation be known with some confidence but also places stringent requirements on the ability to determine this quantity.

One final point pertinent to this issue and to the accurate representation of the indirect forcing due to anthropogenic aerosols in climate models concerns the episodic nature of the anthropogenic perturbation in aerosol loading. Because of the concentration of sources in a few highly localized industrial regions, the short residence times of aerosol particles in the troposphere (about a week), the episodic nature of removal processes, which are dominated by precipitation, and the variability of transport winds, concentrations of anthropogenic aerosols at any given location are highly variable temporally. This property is evidenced by time series in a variety of locations of concentrations of aerosol substances and of other indicia of aerosol loadings such as light scattering coefficient and optical depth. In a recent study (Benkovitz et al., 1994) in which the column burden of sulfate aerosol in the mid North Atlantic was calculated with a model that used meteorological variables derived from operational meteorological products, the characteristic autocorrelation time was about 10 hours. The spatial autocorrelation distance was likewise rather short, 400 to $1700 \mathrm{~km}$. This situation is very different from the rather smooth temporal and spatial patterns that are depicted in modeling studies based on monthly average meteorological fields (e.g., Langner and Rodhe, 1991), which have served as the basis for evaluations of the anthropogenic indirect influence, as discussed below. The highly variable nature of the aerosol loading has implications regarding such evaluations in 
view of the nonlinear relation between aerosol loading and the indirect forcing. It also suggests that it may be easier to discern the anthropogenic influence on aerosol loadings by measures that take account of this episodicity than simply by examination of annual or monthly mean loadings.

Anthropogenic influences on cloud droplet concentrations. Anthropogenic influences on cloud droplet concentrations can be examined directly, by consideration of cloud droplet concentrations in air which has been classified according to anthropogenic influence. Alternatively one may examine the relation between aerosol loading and cloud droplet concentrations. While the former approach can certainly establish the existence of such an influence, the latter approach may ultimately prove more valuable by leading to a quantitative relation between anthropogenic emissions and cloud droplet loadings through mechanistic understanding of the governing processes.

It has been recognized for several decades that continental clouds exhibit greater number concentrations than do marine clouds (e.g., Pruppacher and Klett, 1980). Although the reasons for this are not entirely established, it would appear that to great extent the difference lies in the concentration of $\mathrm{CCN}$ in precursor air. In principle cumulus clouds with greater updraft velocities (and therefore greater supersaturation rates) would be expected to exhibit greater droplet number concentrations than stratiform clouds. This expectation is in general borne out, and therefore comparisons must be made for similar cloud types. Still continental clouds tend to exhibit greater drop concentrations. This difference was thought by some to be due to natural sources of aerosols, e.g., particles formed from gas-to-particle conversion of emissions from terrestrial vegetation. However numerous studies linking high cloud drop concentrations to identified combustion sources or other industrial activity have led some to suppose that high cloud drop concentrations in continental clouds may be due largely to anthropogenic emissions (e.g., Mészáros, 1992). We note here a number of these studies.

In a key early study Warner and Twomey (1967) found that the number concentration of droplets in clouds formed downwind of sugar cane fires was greatly increased (average $510 \mathrm{~cm}^{-3}$ ) over that in maritime air upwind (average $104 \mathrm{~cm}^{-3}$ ). In an early study examining urban influences on cloud microphysical properties Fitzgerald and Spyers-Duran (1973) compared the droplet size spectra in small cumulus and stratocumulus clouds upwind and downwind of St. Louis, Missouri. Comparisons on two days are shown in Figure 6. It was found that 

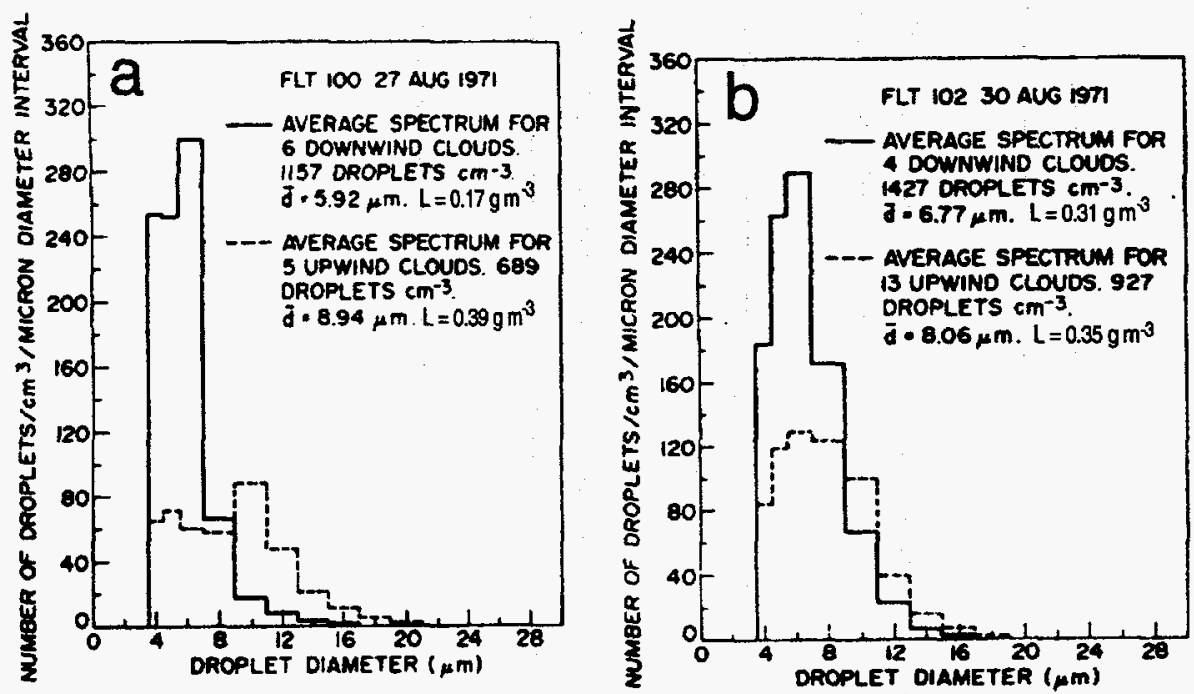

Figure 6. Drop size distributions obtained in cumulus and stratocumulus clouds up- and downwind of St. Louis, Missouri. Note increase in drop concentration and decrease in drop diameter downwind of the city. From Fitzgerald and Spyers-Duran (1973).

clouds downwind of the city were comprised of higher concentrations of smaller droplets that exhibited a narrower dispersion of sizes than upwind clouds. A possible concern with attributing the differences entirely to microphysical changes due to changed $\mathrm{CCN}$ concentrations is the difference in liquid water content, at least in the 27 August data.

A rather direct examination of the influence of urban emissions on the microphysical properties on stratiform clouds was recently conducted by Alkezweeny et al. (1993), who reported measurements of cloud droplet size distributions upwind and downwind of the Denver, Colorado metropolitan area. An example of data from this study is shown in Figure 7a. Here the solid curve
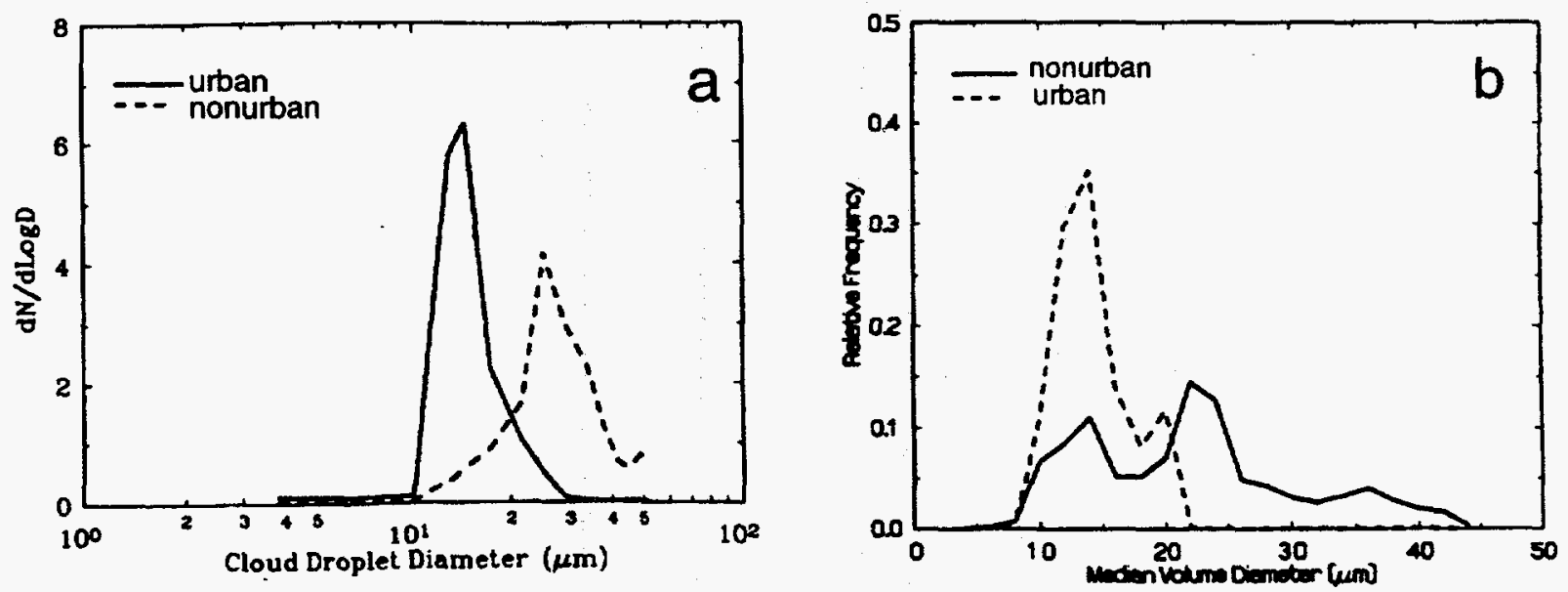

Figure 7. (a) Normalized drop size distributions obtained in vertical profiles in regions of stratiform cloud that were or were not influenced by emissions from Denver, Colorado. (b) Median volume diameter of drop size distributions in stratiform clouds in the vicinity of Denver, according to criterion $\mathrm{NO}_{2}<0.5 \mathrm{ppb}$ (nonurban) or $\mathrm{NO}_{2}>1 \mathrm{ppb}$ (urban). From Alkezweeny et al. (1993). 
represents a composite drop-size spectrum obtained in a vertical profile in urbaninfluenced air and the dashed curve represents similar measurements in nonurban air a few minutes later. The liquid water contents were fairly similar, 0.25 and $0.16 \mathrm{~g} \mathrm{~m}^{-3}$, respectively. However the drop distribution in the urban air is shifted to much smaller diameters than that of the non urban air, with median volume diameter 14 and $28 \mu \mathrm{m}$, respectively. Correspondingly the drop concentration is increased by an order of magnitude, from 22 to $226 \mathrm{~cm}^{-3}$. Figure $7 \mathrm{~b}$ shows a summary of median volume diameters for the study as a whole; here the criterion for urban versus nonurban air was taken as $\mathrm{NO}_{2}$ mixing ratio greater than $1 \mathrm{ppb}$ or less than $0.5 \mathrm{ppb}$, respectively. Despite the somewhat arbitrary nature of the criterion, it is clear that clouds in "urban" air frequently exhibit a considerably reduced drop size relative to clouds in the control "nonurban" air. These measurements likewise establish a strong sensitivity of drop number and drop size to urban emissions.

Evidence of the influence of enhanced aerosol particle concentrations on the concentration of cloud droplets in marine stratus and stratocumulus clouds comes from so-called "ship tracks", linear features of high cloud reflectivity embedded in such clouds that apparently form on aerosol particles released in the exhaust from the engines of ships (Coakley et al., 1987; Scorer, 1987; Radke et al., 1989). Aircraft penetrations through ship tracks have confirmed the supposition of enhanced droplet concentrations and decreased drop radius associated with the ship tracks compared to adjacent unperturbed regions of the clouds: $120 \mathrm{~cm}^{-3}$ vs. $40 \mathrm{~cm}^{-3}$ and $7.5 \mu \mathrm{m}$ vs. $11.2 \mu \mathrm{m}$, respectively (Radke et al., 1989; King et al., 1993).

In an examination of anthropogenic influences on cloud microphysical properties at somewhat greater distances from sources, Pueschel et al. (1986) reported measurements of microphysical properties and chemical composition of clouds at Whiteface Mountain in rural upstate New York (elevation $1500 \mathrm{~m}$ above sea level). Table 2 shows a comparison of measurements on three days for which airmass back trajectories indicated distinctly different sources of the air in which the clouds were formed. The cloud droplet concentration increased dramatically with aerosol loading, which, in turn, on the basis of the back trajectory, was ascribed to anthropogenic emissions, certainly in the case of the trajectory that passed in the vicinity of Pittsburgh, Pennsylvania, compared to the background continental and maritime trajectories. 
Table 2. Comparison of accumulation-mode aerosol particle concentration (0.2-1.0 $\mu \mathrm{m}$ diameter), cloud droplet concentration (0.5-47 $\mu \mathrm{m}$ diameter), and sulfate concentration in cloudwater as a function of air-mass back trajectory for samples at Whiteface Mountain, New York, in June 1981. Data of Pueschel et al. (1986).

\begin{tabular}{llcccc}
\hline Date, 1981 & Air-mass back trajectory & $\begin{array}{l}N_{\mathrm{cd}} \\
\mathrm{cm}^{-3}\end{array}$ & $\begin{array}{l}N_{\mathrm{cd}}, \\
\mathrm{cm}^{-3}\end{array}$ & $\begin{array}{l}F= \\
N_{\mathrm{cd}} /\left(N_{\mathrm{cd}}+N_{\mathrm{cd}}\right)\end{array}$ & $\begin{array}{c}\text { Sulfate , } \\
\mu \mathrm{mol} \mathrm{L}\end{array}$ \\
\hline $\begin{array}{l}\text { 26 June } \\
\text { 0819-0836 }\end{array}$ & $\begin{array}{l}\text { Maritime; St. Lawrence Estuary, } \\
\text { Gaspé Peninsula }\end{array}$ & 63 & 64 & 0.50 & 6.5 \\
$\begin{array}{l}\text { 23 June } \\
\text { 0845-0944 }\end{array}$ & $\begin{array}{l}\text { Background continental; north of } \\
\text { Lake Superior }\end{array}$ & 219 & 127 & 0.37 & 21 \\
$\begin{array}{l}\text { 25June } \\
\text { 0859-0955 }\end{array}$ & $\begin{array}{l}\text { Polluted continental; Pittsburgh, } \\
\text { Pennsylvania }\end{array}$ & 3060 & 750 & 0.20 & 237 \\
\hline
\end{tabular}

Several studies have reported relations between cloud drop concentration and concentrations of aerosol particles or of $\mathrm{CCN}$ in pre-cloud air or interstitial cloud air, from which inferences may be drawn regarding the sensitivity of cloud drop concentrations to anthropogenic influences. Figure 8 shows a plot of cloud droplet concentration vs. below-cloud concentration of $\mathrm{CCN}$ active at an updraft velocity of $3 \mathrm{~m} \mathrm{~s}^{-1}$ presented by Twomey and Warner (1967). An approximately one-to-one relation was observed over the entire concentration range studied, up to about $1000 \mathrm{~cm}^{-3}$.

Considerably different results were obtained by Pueschel et al. (1986) in their examination (at Whiteface Mountain, New York) of the sensitivity of cloud droplet concentration to increasing total in-cloud particle concentration, $N_{\text {tot }}=$

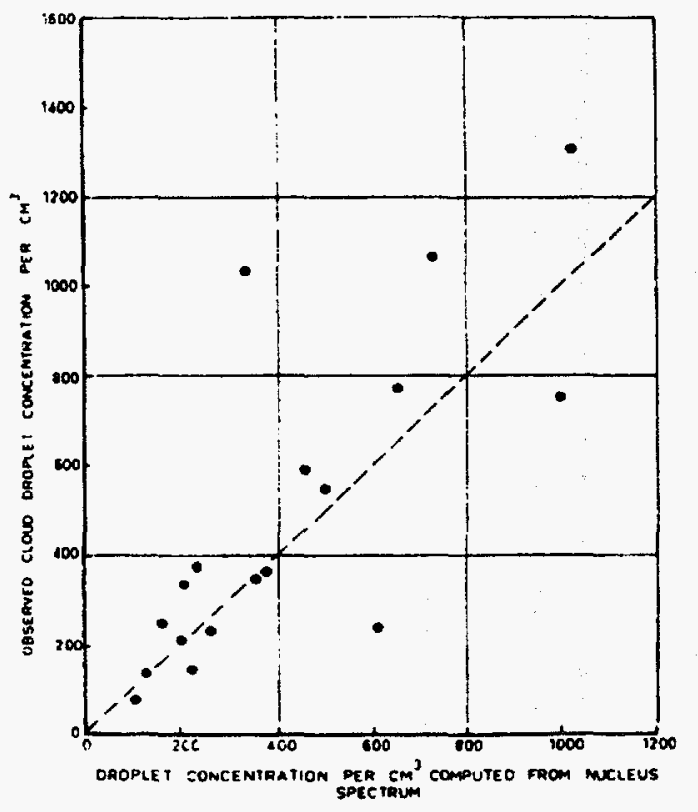

Figure 8. Dependence of cloud droplet concentration $N_{\text {cd }}$ on below-cloud concentration of $\mathrm{CCN}$ active at vertical velocity of $3 \mathrm{~m} \mathrm{~s}^{-1}$ or less. Dashed line shows one-to-one correspondence. From Twomey and Warner (1967). 


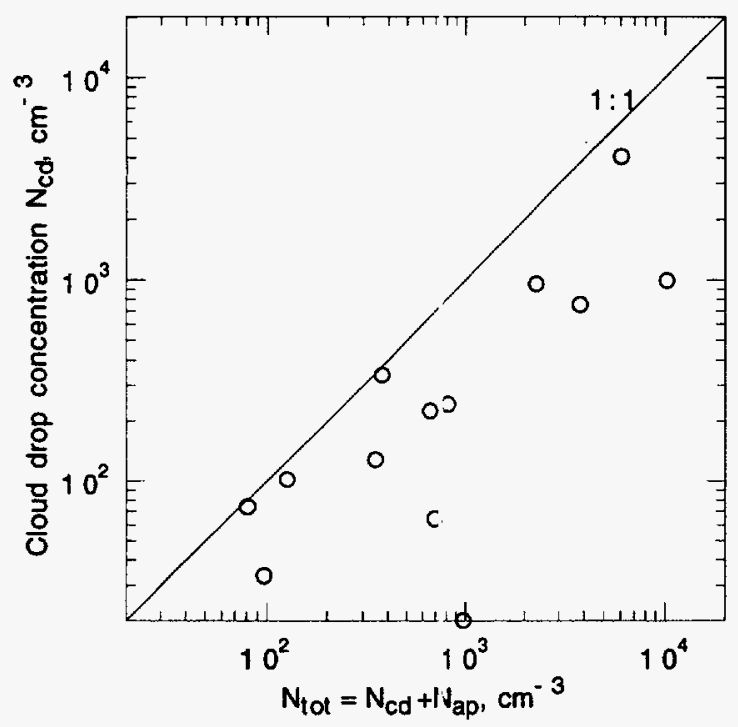

Figure 9. Dependence of cloud droplet number concentration $N_{\mathrm{cd}}$, on total particle number concentration $N_{\text {tot }}=N_{\text {cd }}+N_{\text {ap }}$. Here cloud droplets (cd) encompass the range 0.5 to $47 \mu \mathrm{m}$ diameter and accumulation-mode aerosol particles (ap) the range 0.1 to $3 \mu \mathrm{m}$ diameter. Data of Pueschel et al. (1986) obtained at Whiteface Mountain in rural upstate New York (elevation $1500 \mathrm{~m}$ above sea level) in June 1981.

$N_{\text {cd }}+N_{\text {ap; }}$, here cloud droplets (cd) denote particles in the diameter range 0.5 to 47 $\mu \mathrm{m}$ and accumulation-mode aerosol particles (ap) denote particles in the diameter range 0.1 to $3 \mu \mathrm{m}$. The results are summarized in Figure 9. Quite wide ranges were encountered of both cloud droplet concentrations (up to $4000 \mathrm{~cm}^{-3}$ ) and total particle concentrations (up to $10^{4} \mathrm{~cm}^{-3}$ ). In some instances the cloud droplet concentration was a substantial fraction of the total number concentration, with some tendency for this fraction to decrease with increasing $N_{\text {tot, }}$ whereas in other instances the cloud droplet fraction of the whole was quite small.

Raga and Jonas (1993) compared concentrations of cloud droplets (2 to $47 \mu \mathrm{m}$ diameter) near the tops of low-updraft-velocity marine cumulus clouds to concentrations of below-cloud accumulation-mode aerosol particles ( 0.1 to $3 \mu \mathrm{m}$ diameter), Figure 10. Again a wide range of aerosol particle concentrations was encountered, 50 to $50100 \mathrm{~cm}^{-3}$. The sensitivity of cloud droplet concentration to aerosol particle concentration was much lower than that observed by Twomey and Warner (1967) or by Pueschel et al. (1986).

Martin et al. (1994) compared concentrations of cloud droplets (0.5 to $47 \mu \mathrm{m}$ diameter) in warm st:atocumulus clouds to concentrations of aerosol particles ( 0.1 to $3 \mu \mathrm{m}$ diameter) in air just below cloud base (Figure 11). At low aerosol particles characteristic of air relatively free of anthropogenic influence the concentration of cloud drops was nearly equal to the concentration of aerosol particles, whereas there was a marked fall off at higher aerosol particle concentrations $\left(\gtrsim 400 \mathrm{~cm}^{-3}\right)$ characteristic of anthropogenic influence. 

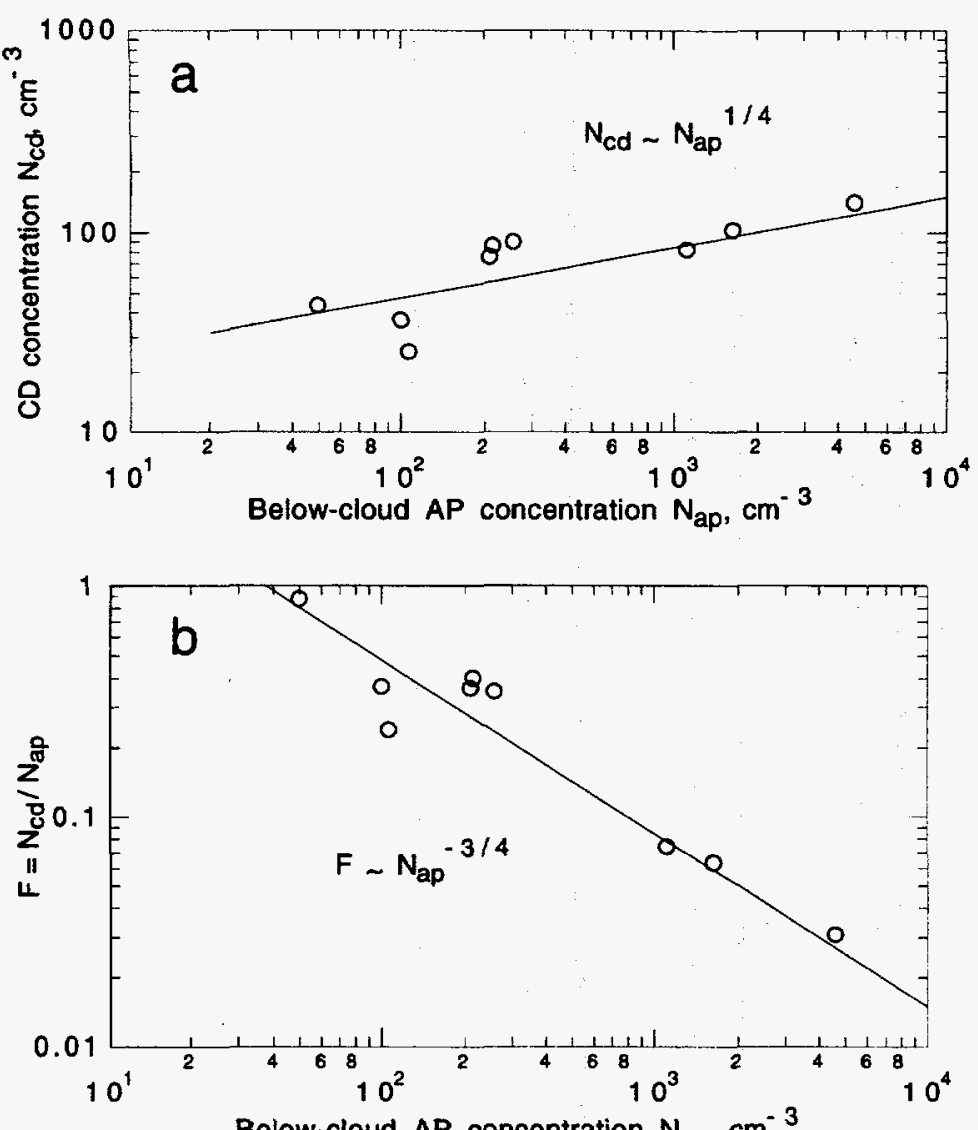

Figure 10. Dependence of cloud droplet concentration $N_{\mathrm{cd}}$ on belowcloud accumulation-mode aerosol particle concentration $N_{\text {ap }}$ for marine cumulus (data of Raga and Jonas, 1993). Panel (a) shows an approximate $1 / 4$ power dependence of $N_{\text {cd }}$ on $N_{\text {ap }}$ over a wide range of $N_{\mathrm{ap}}$. Panel (b) shows the corresponding fractional incorporation of aerosol particles approaching unity at low $N_{\text {ap }}$ but falling off considerably with increasing $N_{\text {ap }}$.

Gillani et al. (1992 a, b) simultaneously measured concentrations of cloud droplets $N_{\text {cd }}$ ( 2 to $47 \mu \mathrm{m}$ diameter) and interstitial accumulation mode particles $N_{\text {ap }}(0.1$ to $3 \mu \mathrm{m}$ diameter) in stratiform clouds in the vicinity of Syracuse New York. Results were reported in terms of the fraction of total particles present as cloud droplets, $F \equiv N_{\mathrm{cd}} / N_{\text {tot }}$, where $N_{\text {tot }}=N_{\mathrm{cd}}+N_{\text {ap }}$. Examples of time series of $F$ from this study are shown in Figure 12. For the measurements shown in panel (a) $F$ is

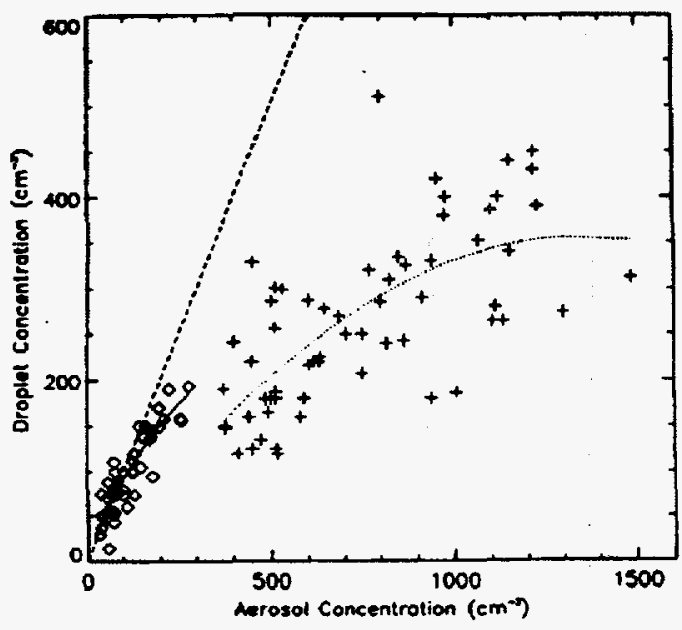

Figure 11. Comparison of concentrations of cloud droplets ( 0.5 to $47 \mu \mathrm{m}$ diameter) in warm stratocumulus clouds to the concentrations of aerosol particles $(0.1$ to $3 \mu \mathrm{m}$ diameter) in air just below cloud base. $\diamond$, Maritime airmasses; +, continental airmasses. The solid line is the best-fit curve for maritime airmasses, the dotted line the best-fit curve for the continental air masses, and the dashed line is $y=x$. From Martin et al. (1994). 

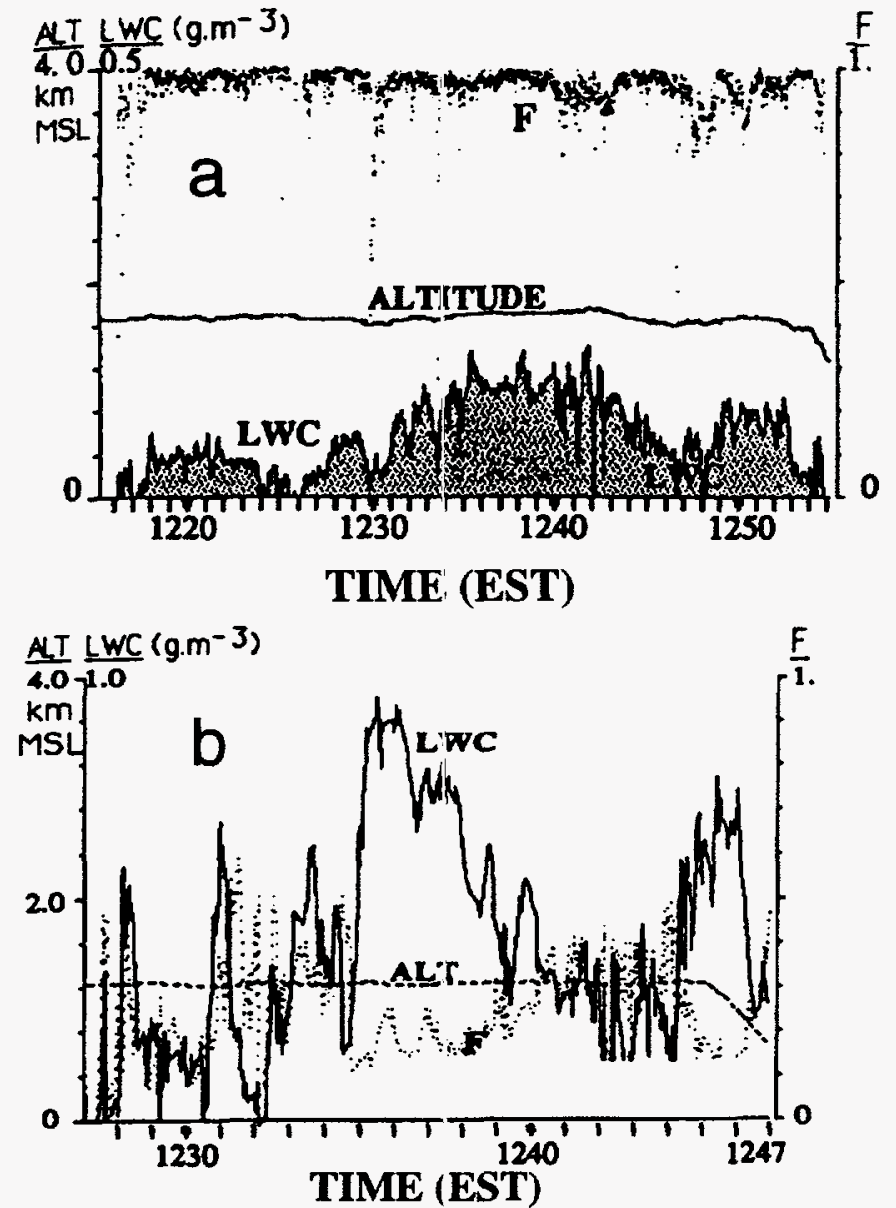

Figure 12. Time series of liquid water content (LWC) and altitude (left ordinates) and fractional incorporation of aerosol particles $F=N_{\mathrm{cd}} /\left(N_{\mathrm{cd}}+N_{\mathrm{ap}}\right)$ measured during aircraft flights in liquid water stratiform clouds in vicinity of Syracuse, New York on two different dates. Panel (a) (cloud layer 14 in Figure 13) shows instance of uniformly high $F$, whereas panel (b) (cloud layer 2 in Figure 13) shows instance of low and variable $F$, both in continuous cloud decks. Gillani et al. (1992a).

near unity throughout the time period shown, whereas for those in panel (b) $F$ is substantially below unity. Figure 13a shows a plot of $F$ against $N_{\text {tot }}$ for the 19 cloud layers examined in this study, indicating that $F$ is near unity at low $N_{\text {tot }}$ ( $\leqslant 300 \mathrm{~cm}^{-3}$ ), but decreases with increasing $N_{\text {tot }}$, suggestive of a possible reduction of maximum supersaturation resulting from competition for water vapor by increased particle concentrations. However at any given value of $N_{\text {tot }}$ substantial variability in $F$ was cibserved, especially at higher values of $N_{\text {tot }}$. Figure $13 \mathrm{~b}$ shows the measurements of $F$ plotted against mean lapse rate in the cloud taken as a surrogate for updraft velocity, which was not measured, and, in any event, is very difficult to deterrnine. The correlation here is as great as in the plot versus $N_{\text {tot}}$, with $F$ increasing with increasing instability in the cloud layer. It is instructive, to locate particular cloud layers in the two figures. Thus cloud layers 4 and 10, which exhibit highly differing values of $F$ for the same value of $N_{\text {tot }}$, are seen to arise from situations having very different lapse rates. Likewise layers 1 and 3, which seem low in the plot of $F$ vs. lapse rate, are characterized by high particle concentrations. The mutual dependence of $F$ on $N_{\text {tot }}$ and vertical velocity 

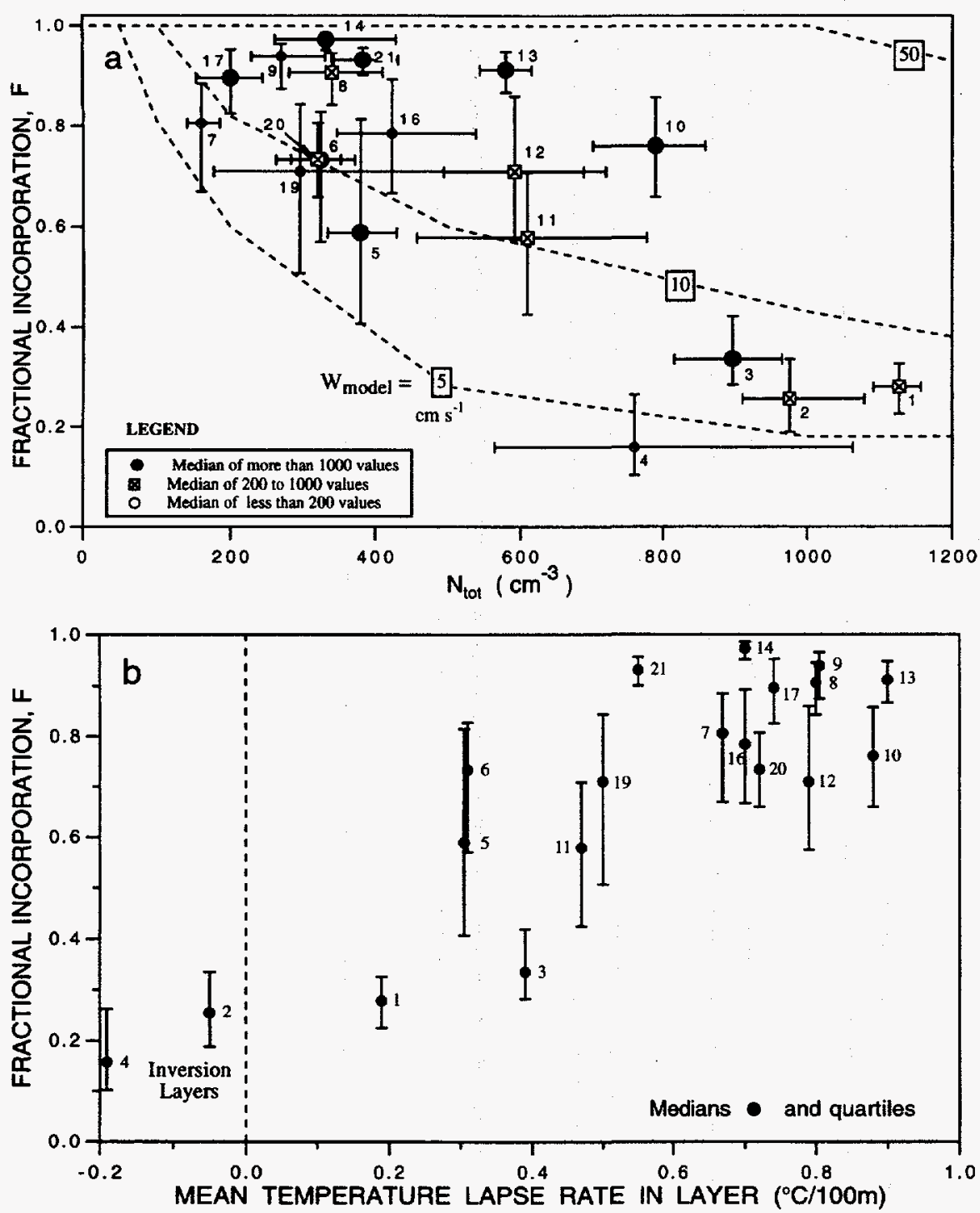

Figure 13. Dependence of $F=N_{\text {cd }} / N_{\text {tot }}$ on $N_{\text {tot }}$ $=N_{\text {cd }}+N_{\text {ap }}$ (a) and on mean lapse rate in cloud layer (b) in 19 liquid water stratiform cloud layers sampled in the vicinity of Syracuse New York. Panel (a) shows decreasing tendency of $F$ with $N_{\text {tot }}$ whereas panel (b) shows sensitivity of $F$ to stability, a surrogate for updraft velocity. Dashed curves in (a) show calculated fractional scavenging efficiency for assumed aerosol particle size distribution as a function of $N_{\text {tot }}$ and indicated updraft velocities $\left(\mathrm{cm} \mathrm{s}^{-1}\right)$. Gillani et al. (1992b).

is supported by model calculations shown by the dashed lines in Figure 13a. Thus while such an explanation probably does not account for all the variability in $F$, including the within-layer variability, it suggests that the observations are at least broadly consistent with the understanding represented in the model.

Another approach to the sensitivity of cloud droplet or CCN concentrations to anthropogenic influences is by direct examination of the dependence of these concentrations to simultaneously measured mass concentrations of a specified substance, such as sulfate or acidity. For reasons indicated above sulfate is expected to exert a dominant influence on cloud droplet concentrations. Several investigators have examined the relation between $N_{\mathrm{ccn}}$ or $N_{\mathrm{cd}}$ and sulfate concentrations in a variety of locations from industrially influenced to pristine; a 

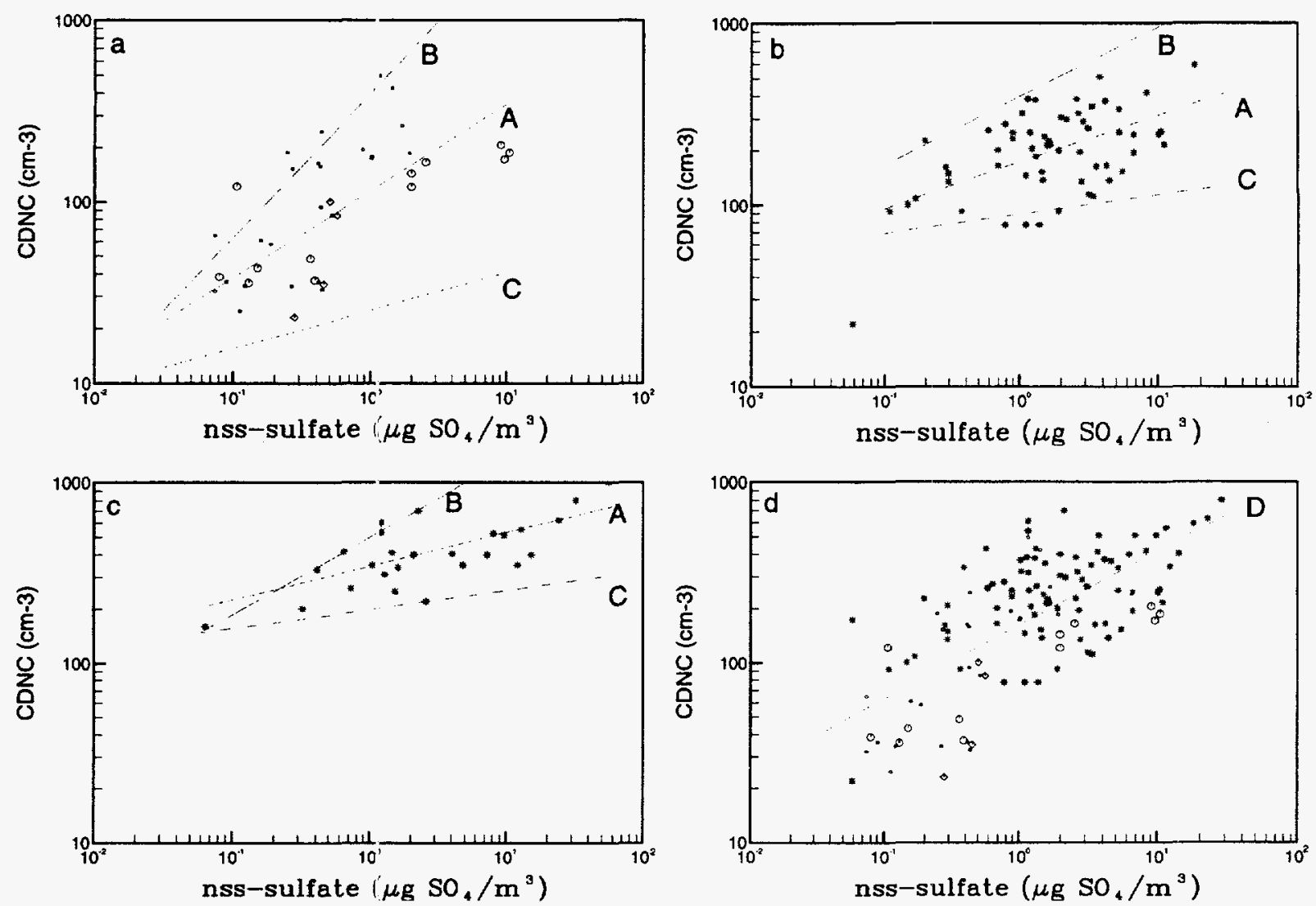

Figure 14. Dependence of cloud droplet or CCN concentration on non-seasalt sulfate aerosol mass concentration for (a) maritime clouds; (b) continental stratiform clouds; (c) continental cumuliform clouds, and (d) all data. The three lines A-C correspond to the mean regression line and the maximum and minimum envelopes, respectively, for each of the data sets. The line D is a regression fit to the entire data set. Sources of the data are: $(*)$ Leaitch et al. (1992); $(\diamond)$ Quinn et al. (1993); ( $\odot)$ Hegg et al. (1993); ( $)$ Berresheim et al. (1993); and (॰) Van Dingenen et al. (1995). From Boucher and Lohmanrı (1995).

number of such comparisons, classified according to cloud type, have been summarized by Boucher and Lohmann (1995) and are shown in Figure 14: aircraft measurements of cloud droplet concentrations, central Ontario and upper New York state, Leaitch et al. (1992); shipboard measurements of CCN active at $0.3 \%$ supersaturation, northeast Pacific Ocean, Quinn et al. (1993); aircraft measurements of CCN active at $1 \%$ supersaturation, northeast Atlantic Ocean, Hegg et al. (1993); CC.N active at $0.3 \%$ supersaturation in maritime air, coastal northwest Washington state, Berresheim et al. (1993); shipboard measurements of aerosol particles that are inferred to have previously been cloud droplet nuclei, North Atlantic Ocean, Van Dingenen et al. (1995). The sensitivities indicated by the slopes on the double logarithmic plots are substantially less than unity, 


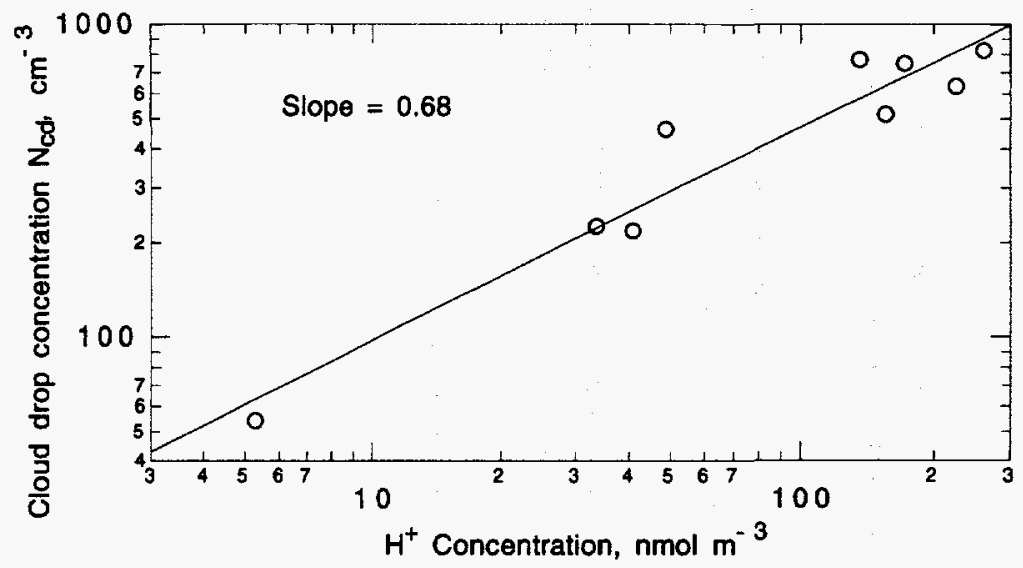

Figure 15. Dependence of cloud droplet concentration $N_{\mathrm{cd}}$ on cloudwater acidity (product of $\mathrm{H}^{+}$concentration and liquid water content) at Mount Mitchell, North Carolina (elevation $2000 \mathrm{~m}$ ). Evaluated from data of Grovenstein et al. (1994).

ranging from about 0.2 (continental) to 0.5 (maritime). A similar low sensitivity in maritime air at El Yunque peak, Puerto Rico, ( $1000 \mathrm{~m}$ elevation) is reported by Novakov et al. (1994). In contrast Grovenstein et al. (1994) present measurements at Mt. Mitchell in rural North Carolina (elevation $2000 \mathrm{~m}$ ) of $N_{\mathrm{cd}}$ and cloudwater $\mathrm{pH}$. A double logarithmic plot of $N_{\mathrm{cd}}$ versus cloudwater acidity (product of $\mathrm{H}^{+}$aqueous concentration and liquid water content) shows a fairly high sensitivity (slope 0.68 ), Figure 15. The high acidities ( $\mathrm{pH}$ as low as 3 at liquid water content of $0.2 \mathrm{~cm}^{3} \mathrm{~m}^{-3}$ ) are unequivocally due to anthropogenic emissions.

In summary, the studies to date can be taken as demonstrating a sensitivity of cloud droplet concentration to the influence of anthropogenic aerosols that is consistent with substantial indirect radiative forcing. However there remains much uncertainty in the quantitative description of the relation between cloud droplet concentration and aerosol loading necessary for accurate modeling of this effect. Clearly any such modeling will have to take into account other variables in addition to aerosol loading, such as local updraft velocity, perhaps including turbulent influences.

Studies relating cloud albedo to cloud droplet concentration. Although there is a convincing theoretical relation between cloud albedo and the size distribution of droplets in the cloud, the phenomenon is difficult to demonstrate because of the inherent variability in cloud albedo due to variability in liquid water path. One potentially convincing approach to quantifying the phenomenon is by means of ship tracks, which afford an immediate contrast to proximate unperturbed regions of the cloud. As noted above, an increase in cloud droplet number concentration and decrease in effective radius have been observed in ship tracks compared to adjacent cloud regions and likewise an increase in cloud optical depth (Radke et al., 1989; King et al., 1993). Unfortunately, from the perspective of 
obtaining an unambiguous demonstration of the effect of increased cloud droplet concentration on cloud albedo, the ship tracks reported in this study also exhibited substantially enhanced liquid water content that undoubtedly contributed to the enhancement of cloud albedo associated with the ship tracks. An explanation that has been offered for this is suppression of drizzle resulting from the reduction in cloud droplet size.

A few studies have examined the relation between cloud droplet microphysical properties and cloud albedo, either on short time scales or in longer time averages.

Durkee (1988) presented an image, derived from the $3.7 \mu \mathrm{m}$ channel of the satellite borne Advanced Very High Resolution Radiometer (AVHRR), of enhancement of reflectivity of marine stratus cloud by the urban plume emanating from San Francisco, California, together with in-situ measurements of the cloud droplet mean radius and total aerosol particle concentration. Aerosol particle concentration is enhanced by an order of magnitude in the urban plume. The reflectance closely follows the expected dependence on mean radius in the infrared channel. The lack of a corresponding signal in the visible channel $(0.63$ $\mu \mathrm{m}$ ) was ascribed to confounding variability in the liquid water path.

Kaufman and Nakajima (1993) examined the effect of enhanced aerosol loading on the reflectance (as measured by AVHRR) of low cumulus and stratocumulus clouds over the Brazilian Amazon basin during periods of biomass burning. Smoke loading was inferred from optical depths in clear sky regions proximate to the clouds. A distinct increase was observed in the $3.7 \mu \mathrm{m}$ reflectivity with increasing aerosol loacling. However a similar increase in the visible reflectivity $(0.63 \mu \mathrm{m})$ was not observed; this was attributed to increased absorption in the clouds due to soot within the aerosol offsetting the brightening influence expected from the increased concentration of cloud droplets.

Grovenstein et al. (1994) presented meașurements of cloud albedo, derived from the $0.63 \mu \mathrm{m}$ channel of the AVHRR, together with in situ measurements of cloud microphysical and chemical properties at Mount Mitchell, North Carolina for four different days in summer 1993. Figure 16 shows cloud reflectivity plotted as a function of the concurrent cloud drop concentration; also shown is the dependence on cloud albedo expected from equation (5b). The agreement between observations and theory is surprisingly good, in view of the constancy of liquid water path assumed in derivation of that equation and the inevitable 


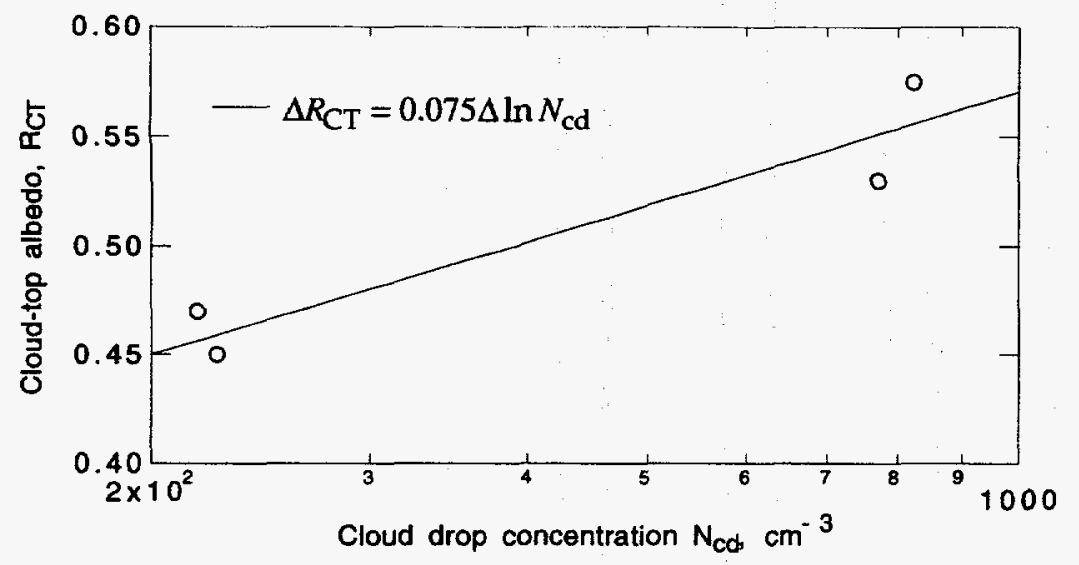

Figure 16. Dependence of cloud albedo at $0.63 \mu \mathrm{m}$ on cloud drop concentration $N_{\text {cd }}$ at Mount Mitchell, North Carolina (elevation $2000 \mathrm{~m}$ ). Evaluated from data of Grovenstein et al. (1994). The line represents the theoretical slope given by Eq (5b).

variability in liquid water path; the liquid water content of the sampled clouds varied from 0.15 to $0.24 \mathrm{~cm}^{3} \mathrm{~m}^{-3}$. Thus although the apparent agreement with theory is very good, it would seem that many more realizations of measurements such as these would be required to build statistical confidence in this relationship.

Boers et al. (1994) examined the relation between monthly mean CCN concentration in marine boundary layer air at Cape Grim, Tasmania and optical depth of low marine clouds (cloud-top pressure greater $680 \mathrm{hPa}$ ) derived from satellite data. The time series of the data are given in Figure 17. Despite considerable scatter a trend of increasing optical depth with increasing $\mathrm{CCN}$ concentration is discernible; in panel (c) a linear fit has been drawn through the data plotted as optical depth versus $(\mathrm{CCN})^{1 / 3}$, as suggested by equation (4). Panel (d) shows the resulting cloud-top albedo calculated by equation (1) from the reported cloud optical depth and from the regression fit. Also shown in that panel is the change in cloud-top albedo evaluated by equation (5). The latter exhibits a much greater dependence on $\mathrm{CCN}$ concentration than is exhibited by the observations. The reasons for this departure are not immediately evident. One possibility, however, is the averaging inherent in the measurements of both the $\mathrm{CCN}$ concentrations and the cloud optical depths. Moreover, optical depth will be influenced by variations in quantities other than $\mathrm{CCN}$ concentrations, notably cloud liquid water path. One may also question the representativeness of the $\mathrm{CCN}$ concentrations in describing the droplet concentrations in the clouds. Nonetheless the markedly lower sensitivity exhibited by the observations than would be expected from equation (4), a factor of 3.5 in slope of albedo versus logarithm of $\mathrm{CCN}$ concentration, raises a major question regarding estimates of shortwave forcing based on this treatment. Clearly the reasons for this discrepancy need to be understood. 

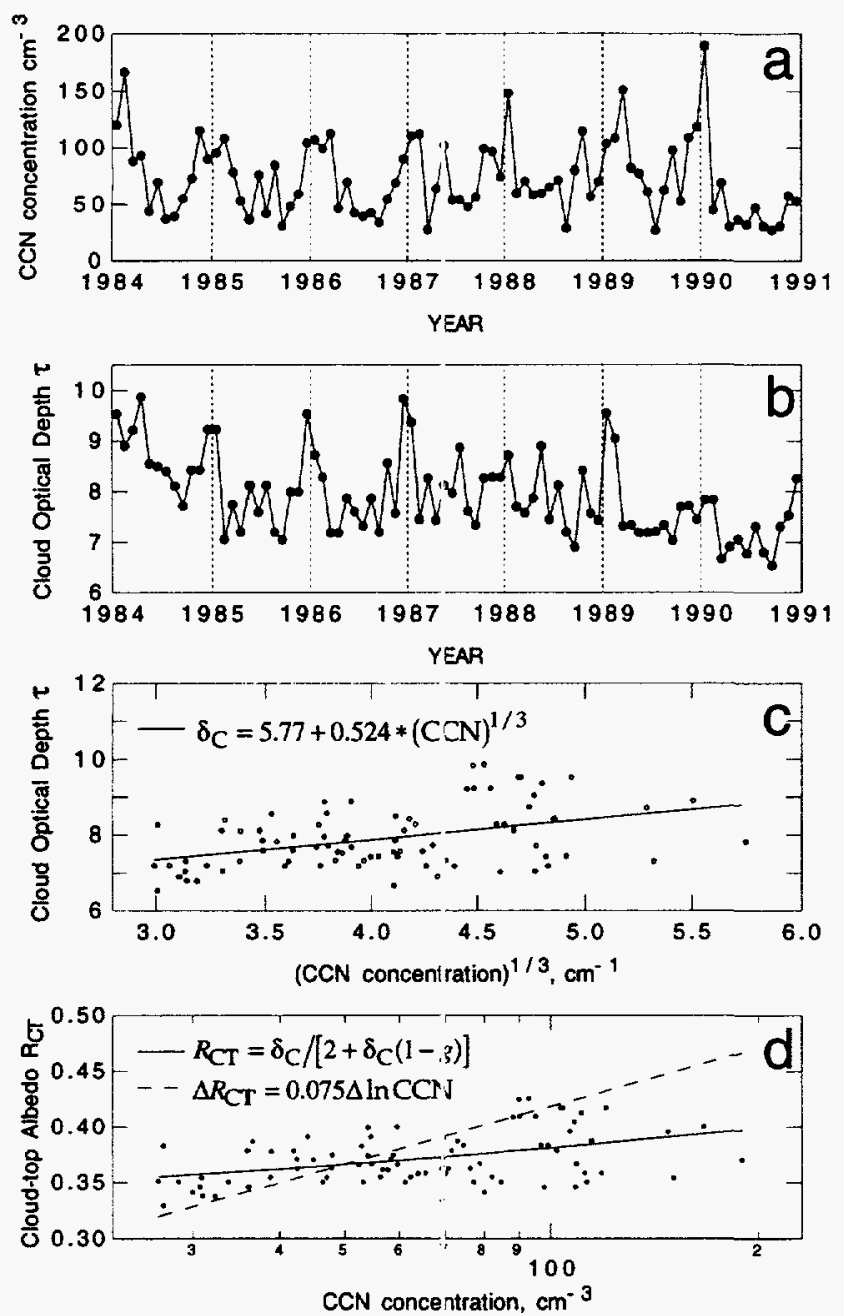

Figure 17. Time series of (a) monthly mean CCN concentration $(100 \mathrm{~m}$ altitude, $0.23 \%$ supersaturation) and (b) monthly mean cloud optical depth at Cape Grim, Tasmania; Data of Boers et al. (1994). Cloud optical depths were derived from ISCCP (International Satellite Cloud Climatology Project) data for the nearest grid point to the Cape Grim station that was fully oceanic, and were restricted to cloud-top pressures greater than $680 \mathrm{hPa}$. Panel (c) shows correlation of optical depth with CCN concentration, where the line represents a linear fit to the data plotted according to Eq (4). Panel (d) shows the corresponding cloud-top albedo evaluated by Eq (1) from the measured optical depth and the corresponding to the regression equation, and also as evaluated by Eq (5b). The slope of the observed dependence of cloud-top albedo on the logarithm of CCN concentration, as represented by the regression fit, is lower by a factor of 3.5 than that given by $\mathrm{Eq}$ (5b).

Attempts to identify correlations of satellite observations of albedo with regions influenced by anthropogenic $\mathrm{SO}_{2}$ emissions have yielded mixed results. Schwartz (1988) atternpted to discern interhemispheric differences (northern versus southern) in the cloud contribution to planetary albedo based on measurements from the Nimbus 3 satellite. A large interhemispheric difference might be expected because anthropogenic emissions are disproportionately concentrated (roughly 90\%) in the northern hemisphere, although the comparison might well be confounded by other interhemispheric differences such as land masses and ocean circulations. Within the uncertainty of the measurements no indication was discerned of enhanced cloud albedo in the northern hemisphere.

Kim and Cess (1993), examined monthly averaged albedo for low-level marine clouds as obtained from the Earth Radiation Budget Experiment (ERBE) as a function of longitude for regions of the North Pacific and North Atlantic expected 
to exhibit influence of anthropogenic aerosols, and compared these to regions of the southern hemisphere, taken as a control. Figure 18 shows an example of these results for April, 1985. Significant trends were observed indicative of albedo enhancement over coastal areas affected by anthropogenic aerosols. However in a similar study Falkowski et al. (1992) found that the monthly averaged albedo of low-level marine stratus clouds over the North Atlantic Ocean obtained from ERBE exhibited correlation with ocean productivity inferred from the Coastal Zone Color Scanner chlorophyll concentrations, but did not exhibit systematic decreases eastward from North America as would be expected if cloud albedo were enhanced by anthropogenic aerosol. They concluded that much of the variability in cloud albedo could be accounted for by biogenic emissions of sulfate precursors.

Recently, Han et al. (1994) examined the latitudinal dependence of drop sizes of warm $(\mathrm{T}>273.2 \mathrm{~K}$ ) clouds, as determined by an algorithm that uses radiances at $3.7 \mu \mathrm{m}$ and $10.8 \mu \mathrm{m}$ determined by the satellite-borne AVHRR radiometer. Four seasonal months were examined, and clouds were distinguished according to whether they were above land or ocean. Figure 19 shows the annual (4-month average) zonal-mean radii derived by this analysis. It is seen first that the effective radius is systematically smaller for continental clouds than for maritime clouds, consistent with the discussion given above. More importantly, with respect to identifying possible anthropogenic influences, there is indication, in both the maritime and continental clouds, of systematically smaller effective
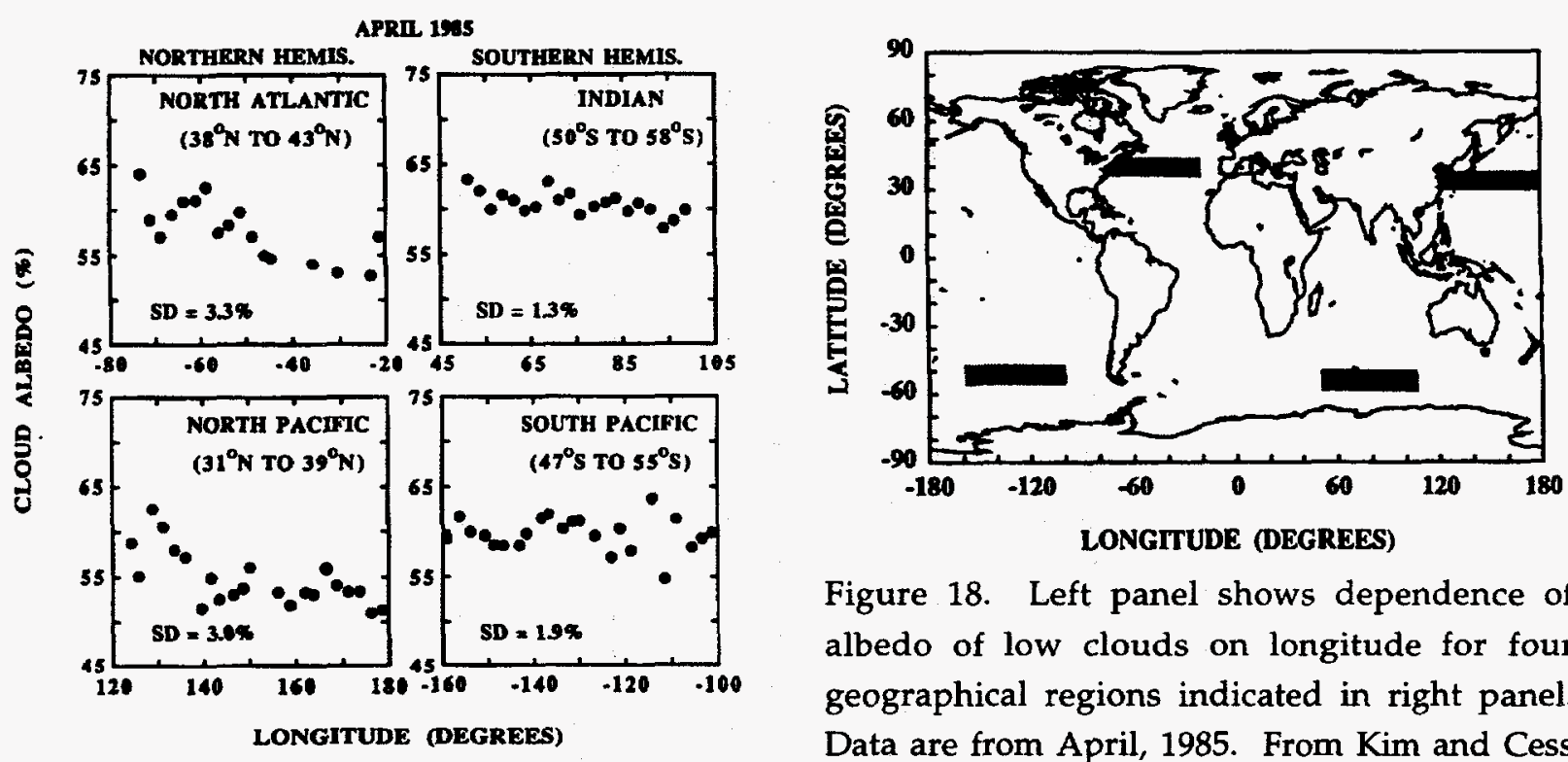

Figure 18. Left panel shows dependence of albedo of low clouds on longitude for four geographical regions indicated in right panel. Data are from April, 1985. From Kim and Cess (1994). 


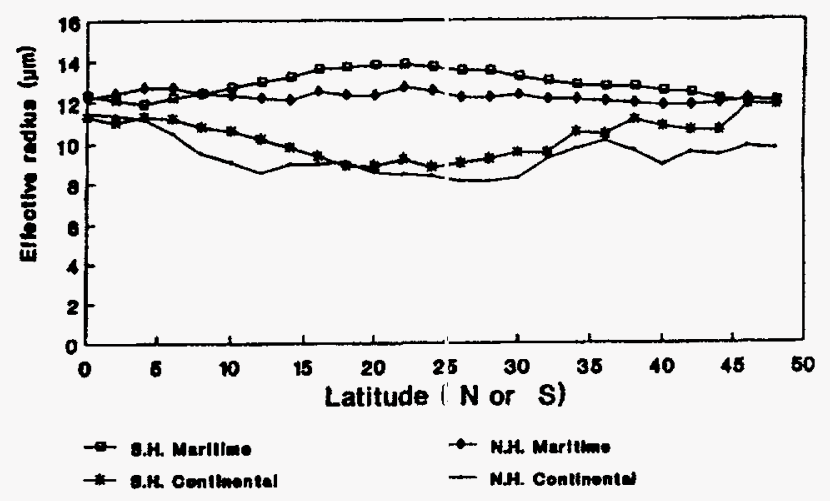

Figure 19. Annual (4-month average) zonal mean water cloud droplet effective radii for 1987 from analysis of NOAA-9 AVHRR radiances. From Han et al. (1994).

radius in mid latitudes of the Northern Hemisphere, consistent with such anthropogenic influerice. Han et al. suggest that because of the effect of the inherent variability in liquid water path on cloud albedo, effective radius is a more sensitive indicator of anthropogenic influence than is cloud albedo:

In summary, despite a great sensitivity in cloud albedo that might be expected due to anthropogenic aerosols, there is scant evidence of this influence from satellite measurements, for example over the North Atlantic. A possible reason for this may be that previous searches for this influence have examined long-time averages, in which fluctuations in liquid water path dominate, especially in view of the short temporal and spatial scales which appear to characterize the variability in the anthropogenic aerosol loading (Benkovitz et al., 1994). On the other hand, examination of effective radius, as has been carried out by Han et al., may prove to be a more sensitive indicator of such influence, especially in shorttime averages.

\section{STUDIES WITH CLIMATE MODELS}

The estimates of the indirect effect discussed at the beginning of this chapter were made with very simple models. These provide initial guidance as to the possible magnitude of the global forcing of the climate system by changes in aerosol concentrations. For a more detailed assessment, especially of the response to the aerosol forcing, it is necessary to use three-dimensional climate models. These have been widely used to study the $\mathrm{CO}_{2}$ problem and more recently the direct aerosol effect (e.g. Taylor and Penner, 1994; Mitchell et al., 1995). As discussed below, they are now being applied to the indirect effect of sulfate aerosols. While such models allow key aspects of the problem to be addressed, such as the geographical distribution of the forcing, it must be appreciated that even the most detailed of present climate models represent cloud microphysical processes only crudely, if at all. The models are slowly being improved in this respect, but there 
are fundamental problems in trying to represent such processes in models whose horizontal resolution is no better than a few hundred kilometers. Cloud microphysical processes and the interactions with aerosols must therefore be parametrized, based on more detailed cloud-resolving models and observational data.

Until recently, the modeling groups working on the development of climate models had little interaction with those developing models of atmospheric chemistry. This situation is changing, because of recognition of the need to treat coupled chemistry-climate problems such as anthropogenic perturbations to the carbon dioxide and ozone distributions and the direct and indirect effects of sulfate aerosols. Fully coupled chemistry-climate models, which are under development in several centers, clearly will be powerful tools for studying the indirect effect. To date, however, the published climate model studies of the indirect effect have been much less ambitious and have concentrated on estimating the geographical distribution of the forcing, to extend the single global values from the simple models. As will be seen, the uncertainties in the overall magnitude of the forcing are so large (in marked contrast to the $\mathrm{CO}_{2}$ problem) that there is much work to be done in this area before considering the feedbacks induced by the forcing.

Given the large uncertainties in the magnitude of the forcing, it might be argued that there is little to be gained from working with three-dimensional climate models, as opposed to the simple models. This might be true if the only parameter of interest was the globally averaged forcing. However, in order to simulate the geographical distribution of the forcing, the climate models must first simulate the geographical distribution of the effective radius $r_{\mathbf{e}}$. With the advent of global satellite retrievals of $r_{\mathrm{e}}$ such as those of Han et al. (1994), it is now possible to evaluate climate models in ways which are not available for simple models. A climate model which is able to reproduce the observed distributions of the top of the atmosphere radiation budget, as well as the cloud amounts, liquid water contents and $r_{\mathrm{e}}$, is clearly a much more powerful tool for studying the indirect forcing than a simple model which cannot be evaluated in this way.

The most advanced climate models now calculate the radiative properties of water clouds from the cloud liquid water content and effective radius $r_{e}$. The liquid water content is modeled explicitly, using a prognostic equation which takes into account the sources and sinks of cloud water (e.g. Smith, 1990). In contrast, $r_{\mathrm{e}}$ is prescribed, usually as a single global value or perhaps as different 
values for land and sea, to approximate the different aerosol characteristics of continental and maritime air masses. In order to study the indirect effect, it is necessary to include $r_{\mathrm{e}}$ as an additional model variable by representing its dependence on the licuid water content and $\mathrm{CCN}$ concentration, and hence on the aerosol particle concentration.

The physical processes which control $r_{\mathrm{e}}$ are described earlier in the chapter. In a cloud-resolving model these processes may be represented by an explicit treatment of the growth of cloud drops, but given the coarse temporal and spatial resolution of a GCM this approach is neither appropriate nor computationally feasible. Instead, this detail is circumvented by parametrizing the relationships found in field studies between the number of cloud drops and the aerosol concentrations.

Two climate model studies of the indirect forcing have recently been conducted (Jones et al., 1994; Boucher and Lohmann, 1995). Both studies employed externally specified distributions of sulfate aerosol calculated by the MOGUNTIA chemical transport model (Langner and Rodhe, 1991), and from these calculated the distribution of cloud drop concentrations. Given the cloud liquid water content it was possible to derive the effective radius $r_{\mathrm{e}}$ and thence the cloud radiative properties. In both studies, it was assumed that the dominant source of $\mathrm{CCN}$ is sulfate aeroso.l. Comparisons between simulations with the present day sulfate distributions and those for pre-industrial conditions provided the estimates of the indirect forcing, expressed in $\mathrm{W} \mathrm{m}^{-2}$.

Jones et al. (1994) used the climate model of the UK Hadley Centre. This model includes the prognostic cloud scheme of Smith (1990), which calculates the cloud amounts and liquid water contents. A control integration of the model was run in order to represent present-day conditions, using the mean sulfate aerosol distribution from the Langner and Rodhe simulations. These distributions are expressed in terms of the aerosol mass loading, so this was transformed to a number concentration by assuming a log-normal size distribution. This was done in order to capitalize on the aircraft data obtained by Martin et al. (1994) for boundary layer stratocumulus clouds in several regions of the globe. Martin et al. showed that there is a good correlation between the number concentration of aerosols in the sub-cloud layer and the number of cloud drops (Figure 11). There is almost a one-to-one correspondence in clean maritime airmasses, but in polluted continental air only a small fraction of the aerosol is activated to become cloud drops. Jones et al. fitted these data with a simple analytic expression, to 
give the number concentration (in $\left.\mathrm{cm}^{-3}\right)$ of cloud droplets $\left(N_{\mathrm{cd}}\right)$ from the aerosol concentration $A$ (also in $\mathrm{cm}^{-3}$ ):

$$
N_{\mathrm{cd}}=375\left(1-e^{-A / 400}\right)
$$

Since the cloud liquid water content $L$ is a predicted variable of the model, it is then a simple matter to derive the effective radius $r_{\mathrm{e}}$ as

$$
r_{e}=\left(3 L / 4 \pi \mathrm{\kappa} N_{\mathrm{cd}}\right)^{1 / 3}
$$

where $\kappa$ was defined in equation (4) and in the present context accounts for the different shapes of maritime and continental drop size distributions. Figure 20 shows the annual-mean $r_{\mathrm{e}}$ distribution from the control integration, for presentday aerosol loadings. This is in reasonable agreement with the satellite retrievals of Han et al. (1994), providing some support for the method, although there are differences which need to be studied further.

Jones et al. (1994) then performed a series of single timestep integrations of the climate model, in which the aerosol distribution was replaced by that for natural
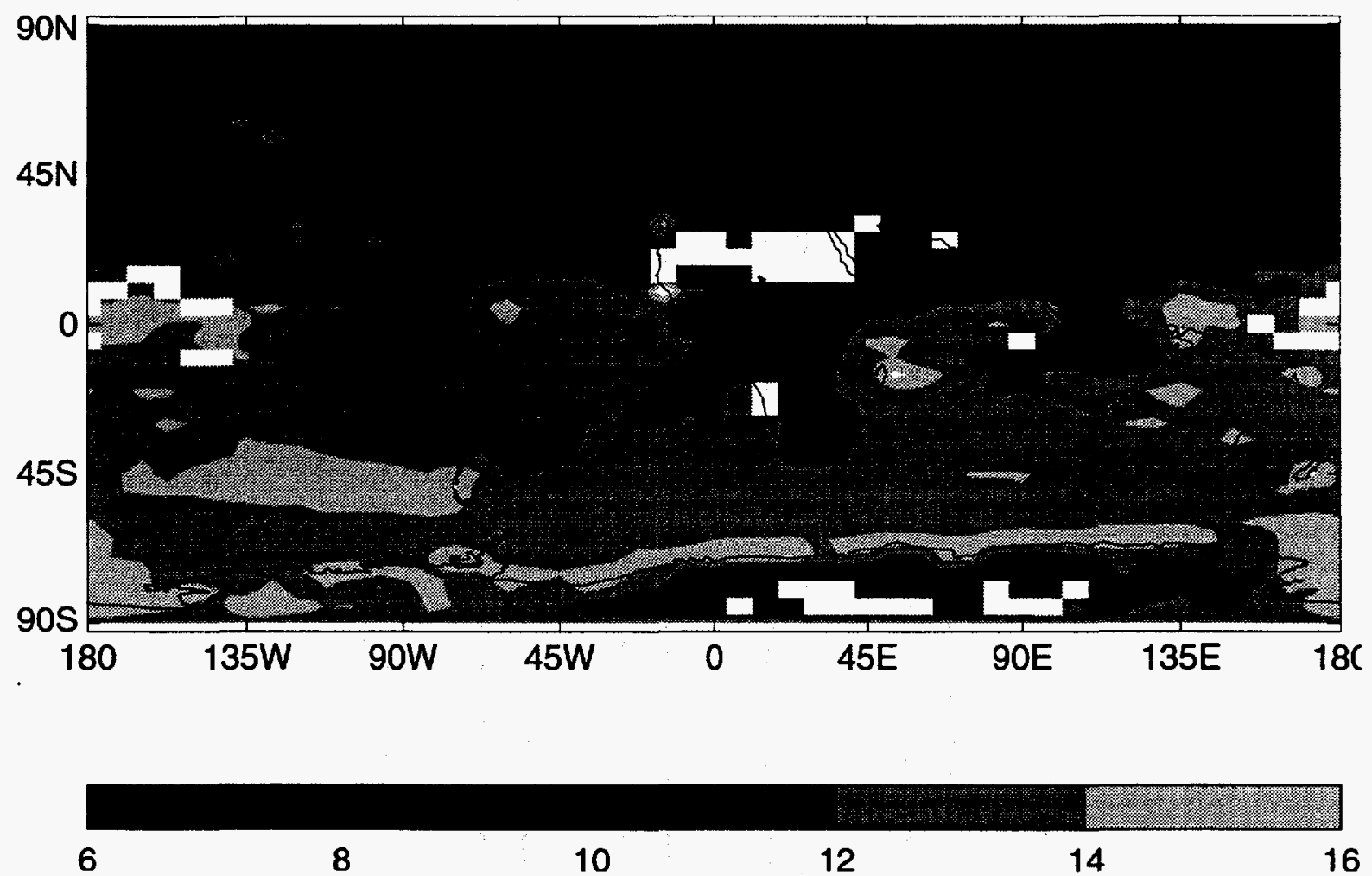

Figure 20. Annual-mean composite of the low cloud droplet effective radius for GCM simulation of the influence of natural and anthropogenic sulfate aerosols on cloud droplet effective radius by Jones et al. (1994). Scale bar indicates droplet radius in $\mu \mathrm{m}$. Mean radius $=11.5 \mu \mathrm{m}$. 
sources only. The difference compared with the control simulation provided the estimate of the current contribution from anthropogenic sulfate to the indirect effect. Figure 21a shows the change in $r_{\mathrm{e}}$ due to the anthropogenic sulfate and Figure $21 \mathrm{~b}$ the corresponding distribution of the associated radiative forcing. The largest increases in $r_{\mathrm{e}}$, of over $4 \mu \mathrm{m}$, are in regions where the anthropogenic contribution to the total sulfate concentrations is largest, such as eastern North America, eastern Europe, and China. These regions are also where the radiative forcing is greatest, peaking at about $-5 \mathrm{~W} \mathrm{~m}^{-2}$. The magnitude of the forcing is also significant in the southern hemisphere, despite the small amount of sulfate pollution. This is due to the high susceptibility of the clouds in such remote regions, where the number concentrations of cloud droplets are low. According to equation (6), this amplifies the sensitivity of the cloud albedo to the sulfate loading and produces a significant radiative perturbation, even for the fairly low incremental sulfate loading. The global average value for the indirect effect obtained by Jones et al. is $-1.3 \mathrm{~W} \mathrm{~m}^{-2}$, although there are considerable uncertainties in this figure. These result from many sources, including the use of the sulfate mass loadings to infer the parameter $A$, the assumed aerosol size distribution, the generality or otherwise of equations (12) and (13), and the sensitivity of the results to the quality of the climate model simulations.

Boucher and Lohmann (1995) performed a rather similar study, although there are several pertinent differences. They compared results from two climate models: the LMD model developed at the Laboratoire de Météorologie Dynamique in Paris and the ECHAM model of the Max Planck Institute for Meteorology in Hamburg. They derived the droplet number concentrations directly from the aerosol mass loadings, by fitting analytic expressions to data from field studies (Figure 14). This is potentially a good approach, as it circumvents the asstimption made by Jones et al. regarding the aerosol size distribution, providec the field studies measure both the sub-cloud sulfate mass loadings and the in-cloud droplet number concentrations. Unfortunately, no such comprehensive measurements have yet been made; for example, Leaitch et al. (1992) made measurements of the cloud water sulfate rather than of the subcloud aerosol, and in other field studies summarized in Figure 14 there were no measurements of the droplet concentrations, which instead were assumed to be the same as the number of $\mathrm{CCN}$ in the sub-cloud layer. This may account for some of the scatter in Figure 14, and further emphasizes the need for more comprehensive field studies. 

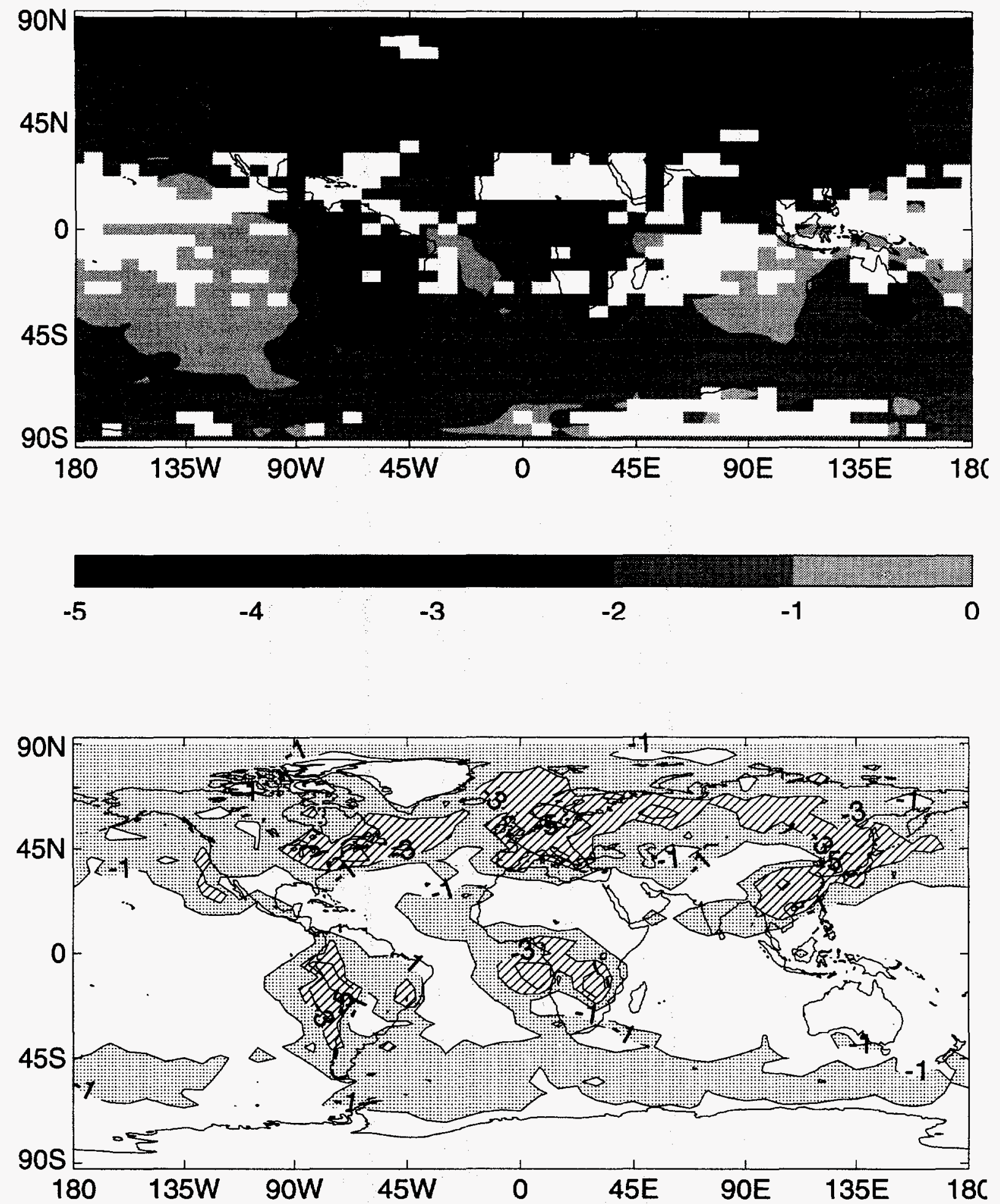

Figure 21. (a) Annual-mean composite of the instantaneous change in low cloud droplet effective radius due to changing from natural-only to total aerosol concentration in the GCM simulation of the influence of sulfate aerosols on cloud droplet effective radius by Jones et al. (1994). Scale bar indicates change in droplet radius in $\mu \mathrm{m}$. Mean change $=-2.2 \mu \mathrm{m}$. (b) Distribution of the indirect radiative forcing due to the change in aerosol concentration, in terms of the change in the top of atmosphere (TOA) net radiation. Mean forcing $=-1.3 \mathrm{~W} \mathrm{~m}^{-2}$. 
Boucher and Lohmanr (1995) fitted regression lines to the data for different cloud types, as well as to the dataset as a whole, and also produced maximum and minimum "envelopes" to assign error bars on the calculated forcing (Figure 14). They evaluated the simulations of $r_{\mathrm{e}}$ by comparing with the Han et al. (1994) retrievals, as was done by Jones et al.

Table 3 lists the estimates of the indirect forcings obtained by Boucher and Lohmann (1995) with the two climate models, for four experiments corresponding to the regression lines A-D shown for the several cloud types in Figure 14. For their rnain experiments (corresponding to regression lines $\mathrm{A}$ and D) the results were very consistent, with a global average forcing of about $-1.0 \mathrm{~W}$ $\mathrm{m}^{-2}$. This is in good agreement with the value obtained by Jones et al. (1994), -1.3 $\mathrm{W} \mathrm{m}^{-2}$, although it should be borne in mind that both studies were based on the same modeled distribution of aerosol sulfate loading. Table 3 also shows a range of values from -0.5 to $-1.5 \mathrm{~W} \mathrm{~m}^{-2}$, but, as pointed out by Boucher and Lohmann, even this rather large cange probably underestimates the true uncertainty. Figure 22 shows the geographical distributions of the forcing from the two climate models for the experiment corresponding to regression line D. The distributions are very similar to those from the Jones et al. study (Figure 21b). These figures emphasize the complex geographical distribution of the indirect forcing,

Table 3. Indirect radiative forcing by sulfate aerosols, for experiments by Boucher and Lohmann (1994) with the LMD and ECHAM climate models.

\begin{tabular}{lllll}
\hline & & \multicolumn{3}{c}{ Forcing $\left(\mathrm{W} \mathrm{m}^{-2}\right)$} \\
\cline { 3 - 5 } Experiment & Model & $\mathrm{NH}$ & $\mathrm{SH}$ & Globe \\
\hline \multirow{2}{*}{$\mathrm{N}$} & LMD & -1.6 & -0.4 & -1.0 \\
& ECHAM & -1.4 & -0.6 & -1.0 \\
B & LMD & -2.2 & -0.6 & -1.4 \\
& ECHAM & -2.1 & -0.9 & -1.5 \\
C & LMD & -0.8 & -0.2 & -0.5 \\
& ECHAM & -0.6 & -0.3 & -0.45 \\
\multirow{2}{*}{$D$} & LMD & -1.7 & -0.4 & -1.05 \\
& ECHAM & -1.6 & -0.6 & -1.1 \\
\hline
\end{tabular}



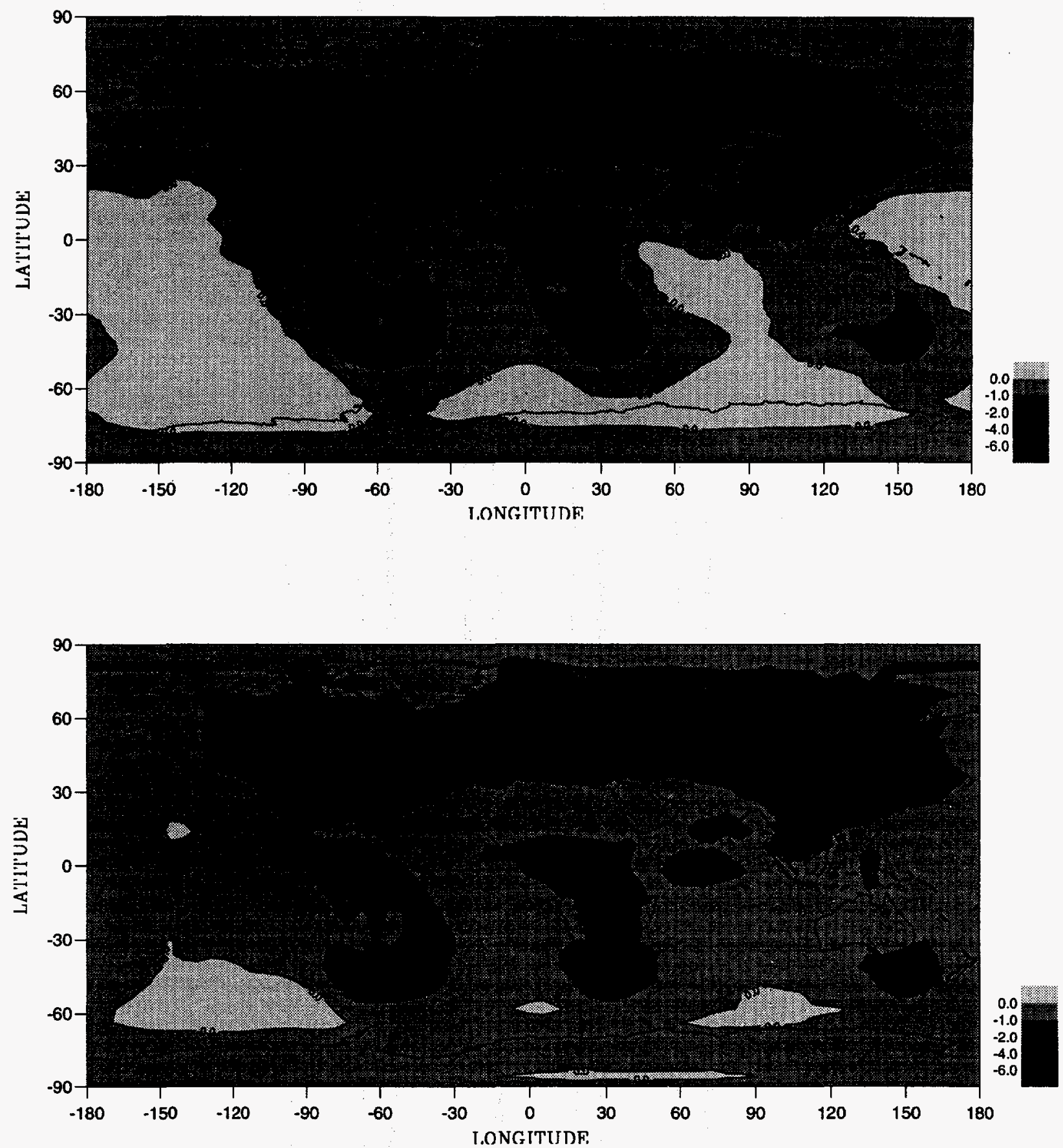

Figure 22. Calculated annual-mean loss of solar irradiance due to the indirect effect of sulfate aerosol for experiment D of Boucher and Lohmann (1995), corresponding the regression D in Figure 14. Top panel gives results for the LMD model and bottom panel for the ECHAM model. Scale bar indicates forcing in $\mathrm{W} \mathrm{m}^{-2}$.

compared with the much smoother distribution of the forcing from increases in trace gases (e.g., Kiehl and Briegleb, 1993).

One of many problems with using three-dimensional climate models to estimate the indirect effect is the difficulty in producing a realistic simulation of $r_{\mathrm{e}}$. 
Boucher (1995) attempted to circumvent this problem by constraining the LMD model with the retrieved values of effective radius obtained by Han et al. (1994). The indirect effect was then estimated from the contrast in $r_{\mathrm{e}}$, and hence in the radiation budget, between the two hemispheres. This is a more direct version of the approach employed by Schwartz (1988). Boucher obtained a value of -0.6 to $-1.0 \mathrm{~W} \mathrm{~m}^{-2}$ for the indirect forcing in the latitude band 0 to $50^{\circ} \mathrm{N}$, in broad agreement with the climate model estimates.

\section{DISCUSSION AND CONCLUSIONS}

The Jones et al. (1994) and Boucher and Lohmann (1995) studies represent first attempts to study the indirect forcing issue with climate models, using externally specified aerosol fields. There are several directions in which this work may be extended.

There is much that needs to be done to reduce uncertainties in the forcing and in its distribution. Both climate model studies used annual-mean sulfate aerosol distributions from the MOGUNTIA model. There is a considerable seasonal cycle in the sulfate concentrations, which needs to be included in the models. Simulations from other chemistry models also need to be included for comparison. Both climate model studies assumed that only sulfate aerosols grow to become cloud drops, but other aerosols are known to be sources of $\mathrm{CCN}$ and should be represented. Some of the disagreements between the $r_{\mathrm{e}}$ distributions from the models and the satellite retrievals of Han et al. (1994) might be caused by this simplification. More detailed comparisons with the satellite data are clearly necessary, as these provide a crucial test of the models. Other methods for predicting the droplet concentrations should also be investigated; this will help to refine the uncertainty limits explored by Boucher and Lohmann. For example, Ghan et al. (1993) have developed a method based on the cloud-scale vertical velocity, although it is a considerable challenge to derive this from the grid-scale variables.

Despite the large uncertainties in the magnitude of the forcing, it is desirable to integrate the climate models forward to study the feedbacks induced by the forcing. One of the first feedbacks to be considered should be that suggested by Albrecht (1989), wherelby increased aerosol concentrations not only brighten the clouds but also suppress the important drizzle mode in boundary layer clouds and so increase the cloud lifetime and areal coverage. Modeling this process 
requires an explicit link between the change in droplet number concentration and the formulation of precipitation processes in the model.

A further step will be to include estimates of the indirect forcing in coupled model simulations of the climate change which has occurred since the industrial revolution and which may occur over the next century. These simulations are performed with coupled ocean-atmosphere models and have only recently included crude representations of the direct aerosol effect. Mitchell et al. (1995) show results which indicate that including the direct aerosol effect in the Hadley Centre coupled model leads to an improvement in the simulation of the past temperature record. It would be valuable to extend such work to include the indirect forcing, although the magnitude is of course even more uncertain than that from the direct effect. Nevertheless, it is important to assess the interaction between both aspects of the sulfate-induced cooling and the greenhouse gas warming, as this may be fundamental to understanding the temperature record over the last century and in making climate predictions for the future.

As noted earlier, several groups are developing coupled chemistry-aerosolclimate models. These will remove the need to specify the sulfate aerosol fields and allow full interaction with the rest of the climate model. Such coupled models will instead specify the geographical distribution of the emissions, allow chemical species and aerosols to be transported by the model winds and removed by sink processes such as dry and wet deposition. There are considerable computational challenges in such developments, but they should enable a much more comprehensive examination of the effects of aerosol on climate than has been possible hitherto. In particular, they will allow the models to represent better the extremely heterogeneous nature of the aerosol distribution in both space and time. The studies performed so far with climate models have used temporally averaged aerosol fields and so fail to represent the episodic nature of the indirect forcing, as the pollution is distributed unevenly by the meteorological fields.

All modeling relies on observations made in the real world to develop parametrizations and evaluate simulations. Comprehensive field experiments are needed which address the many uncertain links in the long chain of interactions leading from the production and transport of the aerosol through to the cloud droplet size and radiative properties. No previous field experiment has studied this problem with sufficient breadth, but such experiments are planned. Of particular concern is the large amount of scatter on Figures 11 and 14, which 
suggests that the relationship between sulfate mass and cloud droplet number concentration is more complex than assumed in the parametrizations used so far. Future field studies should aim to determine the factors which lead to such large scatter, so that more physically based parametrizations can be developed.

Finally, the importance of satellite retrievals of $r_{\mathrm{e}}$ needs to be emphasized again. The retrievals performed by Han et al. (1994) are of great value in assessing the climate model simulations discussed earlier, but much more work is needed to extend the retrievals and to assess their accuracy. Of particular interest is the significant land-sea contrast in these results, the magnitude of which was not simulated well by any of the models. Further retrievals using different methods and data would enable a more comprehensive study of this result. Up to now only time-means of these retrievals have been studied, but it would also be valuable to use the data to perform case studies of aerosol modification of cloud properties and thereby validate the relationship between aerosols and particle size.

Acknowledgments

Work by SES was supported by the Environmental Sciences Division of the U.S. Department of Energy (DOE) as part of the Atmospheric Radiation Measurement Program and was performed under the auspices of DOE under Contract No. DEAC02-76CH00016. Work by AS was supported by the UK Department of the Environment under contract PECD 7/12/37.

\section{REFERENCES}

Ackerman A. S., Toon O. B. and Hobbs P. V. (1993) Dissipation of marine stratiform clouds and collapse of the marine boundary layer due to the depletion of cloud condensation nuclei by clouds. Science 262, 226-229.

Ahr M., I. Flossmann A. and R. Pruppacher H. (1989) A comparison between two formulations for nucleation scavenging. Beitr. Phys. Atmosph. 62, 321-326.

Albrecht B. A. (1989) Aerosols, cloud microphysics, and fractional cloudiness. Science 245, 1227-1230.

Alkezweeny A. J., A. Burrows D. and A. Grainger C. (1993) Measurements of cloud-droplet size distributions in polluted and unpolluted stratiform clouds. J. Appl. Meteorol. 32, 106-115. 
Andreae M. O. (1995) Climate effects of changing atmospheric aerosol levels. In World Survey of Climatology, Vol. XX, Future Climate of the World (edited by Henderson-Sellers A.). In press.

Ayers G. P. and Gras J. L. (1991) Seasonal relationship between cloud condensation nuclei and aerosol methanesulphonate in marine air. Nature 353, 834-835.

Benkovitz C. M., Berkowitz C. M., Easter R. C., Nemesure S., Wagener R. and Schwartz S. E. (1994) Sulfate over the North Atlantic and adjacent continental regions: Evaluation for October and November 1986 using a threedimensional model driven by observation-derived meteorology. J. Geophys. Res. 99, 20725-20756.

Berresheim H., Eisele F. L., Tanner D. J., McInnes L. M., Ramsey-Bell D. C. and Covert D. S. (1993) Atmospheric sulfur chemistry and cloud condensation nuclei $(\mathrm{CCN})$ concentrations over the northeastern Pacific coast. J. Geophys Res. 98, 12701-12711.

Boers R., Ayers G. P. and Gras G. L. (1994) Coherence between seasonal variation in satellite-drived cloud optical depth and boundary layer CCN concentration at a mid-latitude Southern Hemisphere station. Tellus 46B, 123-131.

Bohren C. F. (1987) Multiple scattering of light and some of its observable consequences. Am. J. Phys. 55, 524-533.

Boucher O. (1995) GCM estimate of the indirect aerosol forcing using satelliteretrieved cloud droplet effective radii. J. Clim. 8, 1403-1409.

Boucher O. and Lohmann U. (1995) The sulfate-CCN-cloud albedo effect: A sensitivity study with two general circulation models. Tellus (in press).

Braham R. R. Jr. (1974) Cloud physics of urban weather modification--A preliminary report. Bull. Amer. Meteor. Soc. 55, 100-106.

Charlson R. J. and Heintzenberg J., eds. (1995) Aerosol Forcing of Climate. Wiley, Chichester. In Press.

Charlson R. J., Lovelock J. E., Andreae M. O. and Warren S. G. (1987) Oceanic phytoplankton, atmospheric sulphur, cloud albedo and climate. Nature 326, 655-661. 
Charlson R. J., Lovelock J. E., Andreae M. O. and Warren S. G. (1989) Sulphate aerosols and climate. Nature 340, 437-438.

Charlson R. J., Langner J., Rodhe H., Leovy C. B. and Warren S. G. (1991) Perturbation of the Northern Hemisphere radiative balance by backscattering from anthropogenic aerosols. Tellus 43AB, 152-163.

Charlson R. J., Schwartz S. E., Hales J. M., Cess R. D., Coakley J. A. Jr., Hansen J. E. and Hofmann D. J. (1992) Climate forcing by anthropogenic aerosols. Science $255,423-430$.

Coakley J. A. Jr., Bernstein R. L., and Durkee P. A. (1987) Effect of ship-stack effluents on cloud reflectivity. Science 237, 1020-1022.

Durkee P. A. (1988) Olbservations of aerosol-cloud interactions in satellite-detected visible and near-infrared radiance. In Preprints, Symposium on the Role of Clouds in Atmospheric Chemistry and Global Climate, pp. 157-160, American Meteorological Society, Boston.

Falkowski P., Kim Y., Kolber Z., Wilson C., Wirick C. and Cess R. (1992) Natural versus anthropogenic factors affecting low-level cloud albedo over the North Atlantic. Science 256, 1311-1313.

Fitzgerald J. W. (1991) Marine aerosols: A review. Atmos. Environ. 25A, 533-545.

Fitzgerald J.W. and Spyers-Duran P. A. (1973) Changes in cloud nucleus concentration and cloud droplet size distribution associated with pollution from St. Louis. J. Appl. Meteorol. 12, 511-516.

Flossmann A. I., Hall W. D. and Pruppacher H. R. (1985) A theoretical study of the wet removal of atrnospheric pollutants--Part I. The redistribution of aerosol particles captured through nucleation and impaction scavenging by growing cloud drops. J. Atmos. Sci. 42, 583-606.

Frisbie P. R. and Hudson J. G. (1993) Urban cloud condensation nuclei spectral flux. J. Appl. Meterol. 32, 666-676.

Ghan S. J., Chuang C. C. and Penner J. E. (1993) A parameterization of cloud droplet nucleation. Part I. Single aerosol type. Atmos. Res. 30, 198-221. 
Gillani N. V., Daum P.H., Schwartz S. E., Leaitch W. R., Strapp J. W. and Isaac G. A. (1992a) Fractional activation of accumulation-mode particles in warm continental stratiform clouds. In Proceedings of the Fifth International Conference on Precipitation Scavenging and Atmospheric-Surface Exchange Processes, (edited by Schwartz S. E. and Slinn W. G. N.) pp. 345-358, Hemisphere Publishers, Inc., Washington, DC.

Gillani N. V., Schwartz S. E., Daum P.H., Leaitch W. R., Strapp J. W. and Isaac G. A. (1992b) Fractional activation of accumulation-mode aerosols in continental stratiform clouds. WMO Workshop on Cloud Microphysics and Global Change, Aug., Toronto, Ontario, Canada.

Grovenstein J. D., K. Saxena V. and A. Durkee P. (1994) Impact of anthropogenic and natural aerosols on cloud albedo. Eos. Trans. Geophys. Union 75 (No. 16, Suppl.), 73.

Hallberg A., Ogren J. A., Noone K. J., Okada K., Heintzenberg J. and Svenningsson I. B. (1994) The influence of aerosol particle composition on cloud droplet formation. J. Atmos. Chem. 19, 153-171.

Han Q., Rossow W. B. and Lacis A. A. (1994) Near-global survey of effective droplet radii in liquid water clouds using ISCCP data. J. Climate 7, 465-497.

Hänel G. (1987) The role of aerosol properties during the condensational growth of cloud: A reinvestigation of numerics and microphysics. Beitr. Phys. Atmosph. 60, 321-339.

Hansson H. C. and Svenningsson B. (1994) Aerosols and clouds. In PhysicoChemical Behaviour of Atmospheric Pollutants: Proceedings of the Sixth European Symposium Varese, Italy, Oct. 18-22, 1993, (edited by Angeletti G. and Restelli G.), Vol 2, pp. 837-846. Office of Official Publications of the European Commisssion, Luxembourg.

Hartmann D. L. (1993) Radiative effects of clouds on Earth's climate. In AerosolCloud-Climate Interactions (edited by Hobbs P. V.), pp. 151-173. Academic Press, San Diego.

Hegg D. A. (1990) Heterogeneous production of cloud condensation nuclei in the marine atmosphere. Geophys. Res. Lett. 17, 2165-2168. 
Hegg D. A., Ferek R. J. and Hobbs P. V. (1993) Light scattering and cloud condensation nucleus activity of sulfate aerosol measured over the Northeast Atlantic Ocean. J. Cieophys. Res. 98, 14887-14894.

Hobbs P. V. (1993) Aerosol-Cloud Interactions. In Aerosol-Cloud-Climate Interactions (edited by Hobbs P. V.), pp. 33-73. Academic Press, San Diego.

Hudson J. G. (1991) Observations of anthropogenic cloud condensation nuclei. Atmos. Environ. 25A, 2449-2455.

IPCC (1995). Intergovernmental Panel on Climate Change. Radiative Forcing of Climate Change. In Climate Change 1994 (edited by Houghton J. and Meira Filho L. G.) pp. 1-2:31. Cambridge University Press, Cambridge.

Jensen J. B. and Charlson R. J. (1984) On the efficiency of nucleation scavenging. Tellus 36B, 367-375

Jones A., Roberts D. L. and Slingo A. (1994) A climate model study of indirect radiative forcing by anthropogenic sulphate aerosols. Nature 370, 450-453.

Kaufman Y.J., Fraser R.S. and Mahoney R.L. (1991) Fossil fuel and biomass burning effect on climate--heating or cooling? J. Climate 4, 578-588.

Kaufman Y. J. and Nakajima T. (1993) Effect of Amazon smoke on cloud microphysics and albedo. J. Appl. Meteorl. 32, 729-744.

Kaufman Y. J. and Tanré D. (1994) Effect of variations in supersaturation on the formation of cloud condensation nuclei. Nature 369, 45-48.

Kiehl J. T. and Briegleb B. P. (1993) The relative roles of sulfate aerosols and greenhouse gases in climate forcing. Science 260, 311-314.

Kim Y. and Cess R. D (1993) Effect of anthropogenic sulfate aerosols on low-level cloud albedo over oceans. J. Geophys. Res. 98, 14883-14885.

King M. D., F. Radke L. and V. Hobbs P. (1993) Optical properties of marine stratocumulus clouds modified by ships. J. Geophys. Res. 98, 2729-2739.

Kulmala M., A. Laaksonen, P. Korhonen, T. Vesala and T. Ahonen. (1993) The effect of atmospheric nitric acid vapor on cloud condensation nucleus activation. J. Geophys Res. 98, 22949-22958. 
Langner J. and Rodhe H. (1991) A global three-dimensional model of the tropospheric sulfur cycle. J. Atmos. Chem. 13, 225-263.

Leaitch W. R., Isaac G. A., Strapp J. W., Banic C. M. and Wiebe H. A. (1992) The relationship between cloud droplet number concentrations and anthropogenic pollution: Observations and climatic implications. J. Geophys Res. 97, 24632474.

Lelieveld J. and Heintzenberg J. (1992) Sulfate cooling effect on climate through in-cloud oxidation of anthropogenic $\mathrm{SO}_{2}$. Science 258, 117-120.

Lin X., Chameides W. L., Kiang C. S., Stelson A. W. and Berresheim H. (1992) A model study of the formation of cloud condensation nuclei in remote marine areas. J. Geophys Res. 97, 18161-18171.

Martin G., M., Johnson D. W. and Spice A. (1994) The measurement and parameterization of effective radius of droplets in warm stratiform clouds. $J$. Atmos. Sci. 51, 1823-1842.

Mészáros E. (1992) Structure of continental clouds before the industrial era: A mystery to be solved. Atmos. Environ. 26A, 2469-2470.

Mitchell J. F. B., Johns T. C., J. M. Gregory and S. F. B. Tett. (1995) Transient climate response to increasing sulphate aerosols and greenhouse gases. Nature (in press).

Novakov T. and Penner J. E. (1993) Large contribution of organic aerosols to cloud-condensation nuclei concentrations. Nature 365, 823-826.

Novakov T., Rivera-Carpio C., Penner J. E. and Rogers C. F. (1994) The effect of anthropogenic sulfate aerosols on marine cloud droplet concentrations. Tellus 46B, 132-141.

Penner J. E., Charlson R. J., Hales J. M., Laulainen N., Leifer R., Novakov T., Ogren J., Radke L. F., Schwartz S. E. and Travis L. (1994) Quantifying and minimizing uncertainty of climate forcing by anthropogenic aerosols. Bull. Amer. Meteorol. Soc. 75, 375-400.

Platnick S. E. and Twomey S. (1994) Determining the susceptibility of cloud albedo to changes in droplet concentration with the Advanced Very High Resolution Radiometer. J. Appl. Meteorl. 33, 334-347. 
Pruppacher H. R. and Klett J. D. (1980) Microphysics of Clouds and Precipitation. D. Reidel, Hingham, IMA.

Pueschel R. F., Van Valin C. C., Castillo R. G., Kadlecek J. A. and Ganor E. (1986) Aerosols in polluted versus nonpolluted air masses: Long-range transport and effects on cloucls. J. Clim. Appl. Meteor. 25, 1908-1917.

Quinn P. K., Covert D. S., Bates T. S., Kapustin V. N., Ramsey-Bell D. C. and McInnes L. M. Dirnethylsulfide/cloud condensation nuclei/climate system: Relevant size-resolved measurements of the chemical and physial properties of the atmospheric aerosol particles. J. Geophys. Res. 98, 10411-10427.

Radke L. F. and Hobbs P. V. (1976) Cloud condensation nuclei on the Atlantic seaboard of the United States. Science 193, 999-1002.

Radke L. F., Coakley J. A. Jr., and King M. D. (1989) Direct and remote sensing observations of the effects of ships on clouds. Science 246, 1146-1149.

Raes F. (1995) Entrainment of free tropospheric aerosols as a regulating mechanism for cloud condensation nuclei in the remote marine boundary layer. J. Geophys. Resi. 100, 2893-2903.

Raga G. B. and Jonas P. R. (1993) On the link between cloud-top radiative properties and sub-cloud aerosol concentrations. Quart. J. Roy. Met. Soc. 119, 1419-1425.

Savoie D. L. and Prospero J. M. (1989) Comparison of oceanic and continental sources of non-sea-salt sulphate over the Pacific Ocean. Nature 339, 685-687.

SCEP (Study of Critical Environmental Problems). (1970) Man's Impact on the Global Environment. MIT Press, Cambridge, MA, 319 pp.

Scorer R. S. (1987) Ship trails. Atmos. Environ. 21, 1417-1425.

Schwartz S. E. (1988) Are global cloud albedo and climate controlled by marine phytoplankton? Natire 336, 441-445.

Shine K. P., Derwent R. G., Wuebbles D. J. and Morcrette J.-J. (1990) Radiative forcing of climate. In Climate Change: The IPCC Scientific Assessment (edited by Houghton J. T., Jenkins G. J. and Ephraums J. J.), pp. 41-68. Cambridge Univ. Press, Cambridge. 
Slinn W. G. N. (1992) Structure of continental clouds before the industrial era: A mystery to be solved. Atmos. Environ. 26A, 2471-2473.

Smith R. N. B. (1990) A scheme for predicting layer clouds and their water content in a general circulation model. Quart. J. Roy. Meteor. Soc. 116, 435-460.

Taylor J. P. and A. McHaffie. (1994) Measurements of cloud susceptibility. J. Atmos. Sci. 51, 1298-1306.

Taylor K. E. and Penner J. E. (1994) Response of the climate system to atmospheric aerosols and greenhouse gases. Nature 369, 734-737.

Twomey S. (1974) Pollution and the planetary albedo. Atmos. Environ. 8, 1251-1256.

Twomey S. (1977a) Atmospheric Aerosols. Elsevier, New York.

Twomey S. (1977b) The influence of pollution on the short-wave albedo of clouds, J. Atmos. Sci. 34, 1149-1152.

Twomey S. (1991) Aerosols, clouds and radiation. Atmos. Environ. 25A, 2435-2442.

Twomey S. and Warner J. (1967) Comparison of cloud droplets and cloud nuclei. J. Atmos. Sci. 24, 702-703.

Twomey S., A. Davidson K. and Seton K. J. (1978) Results of five years' observations of cloud nucleus concentration at Robertson, New South Wales. J. Atmos. Sci. 35, 650-656.

Van Dingenen R., Raes F., and Jensen N. R. (1995) Evidence for anthropogenic impact on number concentration and sulphate content of cloud-processed aerosol particles over the North Atlantic. J. Geophys. Res. (in press).

Warner J. and Twomey S. (1967) The production of cloud nuclei by cane fires and the effect on cloud droplet concentration. J. Atmos. Sci. 24, 704-706.

Wigley T. M. L. (1994) Outlook becoming hazier. Nature 369, 709-710.

Wurzler S., Flossmann A. I., Pruppacher H. R. and Schwartz S. E. (1995) The scavenging of nitrate by clouds and precipitation. I. A theoretical study of the uptake and redistribution of $\mathrm{NaNO}_{3}$ particles and $\mathrm{HNO}_{3}$ gas by growing cloud drops using an entraining air parcel model. J. Atmos. Chem. (in press). 